\title{
Dự báo khả năng chịu cắt của dầm bê tông cốt thanh FRP
}

\author{
Nguyễn Việt Phương ${ }^{1}$, Nguyễn Ngọc Phương1, Đặng Vũ Hiệp ${ }^{1}$
}

${ }^{1}$ Khoa Xây dựng, Trường Đại học Kiến Trúc Hà Nội, Km 10, Đường Nguyễn Trãi, Quận Thanh Xuân , TP Hà Nội, Việt Nam

\section{TỪ KHOÁ}

Cốt thanh sợi FRP

Dầm bê tông

Khả năng chịu cắt

Cốt đai

\begin{abstract}
TÓM TẮT
Hiện nay cốt thanh FRP (Fiber-reinforced polymer) đã được chấp nhận rộng rãi trong các cấu kiện bê tông như là loại cốt thay thế cho cốt thép thanh truyền thống do khả năng chống ăn mòn tốt, cường độ cao trong khi trọng lượng riêng nhỏ, không bị ảnh hưởng bởi từ tính. Vì vậy, việc dự báo khả năng chịu lực cho loại cấu kiện này, trong đó có khả năng chịu cắt, là một trong những việc quan trọng trong công tác thiết kế. Bài báo giới thiệu phương pháp dự báo và đánh giá khả năng chịu cắt dầm bê tông cốt thanh FRP theo ba tiêu chuẩn ACI 440.1R-06 (Mỹ), CSA S806-02 (Canada) và JSCE-1997 (Nhật Bản). Qua đó đề xuất một công thức đơn giản để dự báo khả năng chịu cắt của dầm bê tông cốt thanh FRP. Các kết quả dự báo được so sánh với 73 kết quả thực nghiệm thu thập được từ các nghiên cứu được công bố trước đây cho thấy kết quả dự báo theo các tiêu chuẩn thiết kế nêu trên khá an toàn với hệ số biến động lớn, trong khi công thức đề xuất cho kết quả phù hợp hơn với kết quả thực nghiệm và có hệ số biến động nhỏ hơn.
\end{abstract}

\section{KEYWORDS}

FRP bars

Concrete beam

Shear capacity

Stirrups

\begin{abstract}
Currently, Fiber-reinforced polymer (FRP) bars have gained the popupar acceptance as an alternative to conventional steel bars for concrete members due to their corrosion resistance, high strength against low weight, magnetic immunity. Therefore, predicting the strength capacity of such members, particularly the shear capacity is one of the most important issues in design. In this paper, the prediction method and assessment of the shear strength of concrete beams reinforced with FRP bars according to three codes ACI 440.1R-06, CSA S806-02 and JSCE-1997 is presented. The paper then proposes a simple formula to predict the shear strength for FRP bar-reinforced concrete beams. The predicted values are compared with 73 experimental results obtained from previously published researches. The results indicate that the design codes are relatively conservative with large coefficients of variation, while the proposed equation gives results that are in better agreement with the experimental results and a lower coefficient of variation.
\end{abstract}

\section{1. Đặt vấn đề}

Cốt thanh FRP-Fiber Reinforced Polymer được sản xuất có đường kính và chiều dài tương tự như thanh cốt thép truyền thống. Thường có bốn loại sợi hay sử dụng là sợi các bon (C), sợi thủy tinh (G), sợi Ara-mít $(\mathrm{A})$ và sợi bazan $(\mathrm{B})$. Vật liệu này bắt đầu được sử dụng cho các công trình xây dựng vào những năm 80 của thế kỷ trước ở Thụy Sĩ, Đức, Anh, Hà Lan. Sau đó được nghiên cứu phát triển mở rộng sang các nước như Nhật Bản, Mỹ, Canada.

So với cốt thép thường, cốt thanh FRP có rất nhiều ưu điểm như khả năng chống ăn mòn tốt, không bị ảnh hưởng bởi từ tính, cường độ chịu kéo cao, trọng lượng bản thân nhẹ. Do đó hiện nay trên thế giới ngày càng nhiều công trình xây dựng trong vùng xâm thực sử dụng cốt thanh FRP thay thế hoàn toàn hoặc một phần cốt thép truyền thống. Về quan điểm thiết kế chịu lực, có hai vấn đề cần quan tâm nhất khi sử dụng vật liệu FRP. Thứ nhất, vật liệu FRP không có ứng xử dẻo và cường độ chịu kéo thấp tại vị trí bị uốn cong (hiệu ứng bend effect). Điều này có thể dẫn đến việc phá hoại sớm/dòn khi kết cấu chịu uốn hay chịu cắt. Thứ hai, do không có ứng xử dẻo nên sự phân phối lại ứng suất hay mô men hầu như bị giới hạn và do đó khi thiết kế kết cấu cốt thanh FRP không thể sử dụng các phương pháp thiết kế kết cấu bê tông cốt thép truyền thống mà không xem xét thận trọng.

Nghiên cứu thực nghiệm và lý thuyết về sự làm việc chịu cắt của dầm bê tông cốt thanh FRP được nhiều nhà khoa học trên thế giới quan tâm. Chẳng hạn như Bentz cùng cộng sự [1] nghiên cứu thực nghiệm trên 11 dầm bê tông cốt GFRP chịu cắt đã rút ra nhận xét rằng trong dầm sử dụng cả cốt dọc và cốt đai thanh FRP thì dầm sử dụng nhiều lớp cốt dọc có thể bù đắp được hiệu ứng bend effect của cốt đai. Hàm lượng cốt dọc cao dẫn đến góc phá hoại nghiêng nhỏ do đó đóng góp của cốt đai vào khả năng chịu cắt sẽ cao. Issa cùng cộng sự [2] đã thí nghiệm 12 dầm bê tông cốt dọc BFRP có cốt đai BFRP hoặc không có cốt đai, tỷ lệ nhịp chịu cắt, $\mathrm{a} /$ chiều cao làm việc của dầm, $\mathrm{d}$ thay đổi từ 1,5 đến 7,0 . Nhóm nghiên cứu đã rút ra kết luận rằng ngay cả khi tỷ lệ $\mathrm{a} / \mathrm{d}$ cao thì phá hoại cắt vẫn xảy ra trên nhóm dầm không có cốt đai. Khả năng chịu cắt của cả nhóm dầm sử dụng cốt đai và không có cốt đai đều tăng khi hàm lượng cốt dọc BFRP tăng. Gần đây, Jumaa và Yousif [3] khi nghiên cứu hiệu ứng kích cỡ trên các dầm chịu cắt cốt BFRP (cốt dọc và ngang) đã cho rằng không nên bỏ qua hoàn toàn hiệu ứng kích cỡ khi dự báo khả năng chịu cắt của dầm cốt FRP. Sự xuất hiện của cốt đai làm giảm đáng kể hiệu ứng kích cỡ trong dầm. Ở Việt 
Nam, tác giả Huy [4] đã tiến hành nghiên cứu thực nghiệm khả năng chịu cắt dầm bê tông cốt dọc thanh GFRP và cốt dọc thanh thép thường không có cốt đai đã rút ra kết luận rằng khả năng chịu cắt của dầm bê tông cốt dọc thanh GFRP nhỏ hơn khá nhiều so với dầm bê tông cốt thép thường. Ngoài nghiên cứu thực nghiệm, nghiên cứu xây dựng công thức dự báo khả năng chịu cắt cho dầm bê tông cốt thanh FRP cũng được nhiều nhà nghiên cứu quan tâm. Theo đó, hai nhóm phương pháp tiếp cận chính để thiết lập công thức dự báo là phương pháp lý thuyết dẻo biên dưới (mô hình dàn) và phương pháp lý thuyết dẻo biên trên (mô hình đường chảy dẻo nghiêng). Razaqpur và Spadea [5] đã nghiên cứu cơ chế truyền lực cắt trong dầm bê tông cốt thanh FRP dựa trên mô hình dàn với góc nghiêng thay đổi. Kết quả nghiên cứu đã chỉ ra hai tham số quan trọng ảnh hưởng đến khả năng chịu cắt của dầm cốt thanh FRP là góc nghiêng và cường độ bê tông chịu nén thiết kế của thanh chống. Góc nghiêng thanh chống lấy bằng $45^{\circ}$ có thể dự báo quá cao khả năng chịu nén của thanh chống, do đó kiểu phá hoại có thể thay đổi từ phá hoại cốt đai sang phá hoại thanh chống. Kueres và Hegger [6] đã đề nghị một mô hình dàn với góc nghiêng thanh chống thay đổi phụ thuộc vào mô đun đàn hồi, diện tích của cốt đai và biến dạng nén trung bình ở giữa chiều cao dầm. Tương tự như nhận xét của Razaqpur và Spadea [5], các tác giả cũng kết luận góc nghiêng thanh chống đóng vai trò quan trọng trong việc xác định khả năng chịu cắt của dầm bê tông cốt đai FRP. Hơn nữa, cường độ chịu kéo của cốt đai FRP tại vị trí uốn cong có thể lấy bằng 60 \% cường độ chịu kéo trực tiếp của nó. Phương pháp đường chảy dẻo nghiêng kết hợp với tiếp cận cơ học phá hủy được Minh và Rovnak [7] sử dụng để đề xuất một công thức dự báo khả năng chịu cắt của dầm bê tông cốt dọc thanh GFRP. Hoult và cộng sự [8] nghiên cứu dữ liệu thực nghiệm trên 146 mẫu dầm cốt thanh FRP bằng cách sử dụng phương pháp lý thuyết miền nén cải tiến đã được sử dụng cho dầm bê tông cốt thép thường để trả lời câu hỏi liệu sử dụng cốt thanh FRP trong cấu kiện bê tông chịu cắt có làm thay đổi ứng xử cắt so với cấu kiện bê tông cốt thép thường? Nhóm nghiên cứu đã rút ra kết luận rằng không có sự khác nhau về ứng xử cắt giữa cấu kiện bê tông cốt thép thường và cốt thanh FRP không có cốt đai. Do đó hoàn toàn có thể áp dụng được lý thuyết hay công thức đang sử dụng cho cấu kiện bê tông cốt thép vào cấu kiện bê tông cốt thanh FRP. Nhận định này sau đó được Bentz và cộng sự [1] xác nhận lại.

Nhiều tiêu chuẩn tiên tiến trên thế giới như Mỹ [9], Canada [10] và Nhật Bản [11] đã đề cập đến việc thiết kế cho kết cấu bê tông cốt thanh FRP. Điểm giống nhau của các tiêu chuẩn này là sử dụng mô hình dàn kết hợp với hệ số thực nghiệm để dự báo khả năng chịu cắt của dầm cốt thanh FRP. Sức kháng cắt của dầm cốt thanh FRP bằng tổng sức kháng cắt của bê tông chưa nứt cộng với sức kháng cắt của cốt đai nằm trong vết nứt nghiêng (giả thiết vết nứt nghiêng $45^{\circ}$ ). Hiện nay Việt Nam chưa có tiêu chuẩn thiết kế riêng cho loại kết cấu này. Do đó mục đích của bài báo này là trước tiên đánh giá mức độ phù hợp các công thức dự báo khả năng chịu cắt của dầm bê tông tiết diện chữ nhật cốt thanh FRP theo ba tiêu chuẩn Mỹ, Canada và Nhật Bản, sau đó đề xuất một công thức đơn giản dự báo khả năng chịu cắt dựa theo TCVN 5574-2018 [12] cho dầm bê tông cốt thanh FRP và kiểm chứng trên một bộ dữ liệu thực nghiệm được thu thập từ nhiều nghiên cứu độc lập. Công thức đề xuất có hình thức gần với TCVN, thuận tiện cho các nhà thiết kế và xét đến một số đặc tính cơ học của thanh FRP.

\section{Công thức thiết kế trong một số tiêu chuẩn}

2.1 Tiêu chuẩn Mỹ ACI 440.1R-06 [9]

Điều kiện để cấu kiện cốt FRP đảm bảo khả năng chịu cắt dưới tác dụng của tải trọng: $\quad \phi V_{n}>V_{u}$ trong đó: $\phi$ là hệ số giảm độ bền (cấu kiện chịu cắt lấy bằng 0.75 ); $V_{u}$ là lực cắt do tải trọng gây ra; $V_{n}$ là khả năng chịu cắt danh định lấy bằng tổng khả năng chịu cắt của cấu kiện bê tông cốt thanh FRP $\left(V_{c}\right)$ và khả năng chịu cắt của cốt đai thanh $\operatorname{FRP}\left(V_{f}\right)$.

Khả năng chịu cắt của bê tông cốt thanh FRP: $V_{c}=\frac{2}{5} \sqrt{f_{c}^{\prime}} b_{w} c$ trong đó: $f_{c}^{\prime}$ là cường độ nén của mẫu trụ bê tông; $b_{w}$ là bề rộng của bụng cấu kiện; $c$ là chiều cao vùng nén bê tông được lấy bằng $k d$ với $k$ là hệ số chiều cao vùng nén và $d$ là chiều cao làm việc của cấu kiện.

Do cốt FRP không có giới hạn chảy nên để đảm bảo bê tông cốt FRP không bị phá hoại dòn thì cần bố trí lượng đai tối thiểu $A_{f v \text { min }}$ khi $V_{u}>\phi V_{c} / 2$.

Khả năng chịu cắt của cốt đai thanh FRP: $V_{f}=\frac{A_{f v} f_{f v} d}{s}$

trong đó: $A_{f v}$ là tổng diện tích của cốt đai cắt qua vết nứt; $f_{f v}$ là ứng suất trong cốt đai thanh FRP; $s$ là bước đai.

\subsection{Tiêu chuẩn Canada CSA S806-02 [10]}

Tiêu chuẩn chia ra 2 trường hợp dầm: (a) Dầm có đai thanh FRP - xác định theo công thức (4); (b) Dầm có đai thép - xác định theo công thức (5).

$$
\begin{aligned}
& V_{r}=V_{c}+V_{s F} \leq V_{c}+0,6 \lambda \phi_{c} \sqrt{f_{c}^{\prime}} b_{w} d \\
& V_{r}=V_{c}+V_{s s} \leq V_{c}+0,8 \lambda \phi_{c} \sqrt{f_{c}^{\prime}} b_{w} d
\end{aligned}
$$

Khả năng chịu cắt của cốt đai thanh FRP được xác định như sau:

$$
V_{s F}=\frac{0,4 \phi_{f} A_{v} f_{f v} d}{s}<0,6 \lambda \phi_{c} \sqrt{f_{c}^{\prime}} b_{\mathrm{w}} d
$$

Khả năng chịu cắt của bê tông được xác định như sau:

- Khi chiều cao $h \leq 300 \mathrm{~mm}$ hoặc $A_{f v} \geq A_{v, \text { min }}=\frac{0,3 \sqrt{f_{c}} b_{w} s}{f_{f v}}$ :

$0,1 \lambda \phi_{c} \sqrt{f_{c}^{\prime}} b_{\mathrm{w}} d \leq V_{c}=0,035 \lambda \phi_{c}\left(f_{c}^{\prime} \rho_{f l} E_{f} \frac{V_{f} d}{M_{f}}\right)^{\frac{1}{3}} b_{\mathrm{w}} d \leq 0,2 \lambda \phi_{c} \sqrt{f_{c}^{\prime}} b_{\mathrm{w}} d$

- Khi chiều cao $h>300 \mathrm{~mm}$ và $A_{f v}<A_{v, \text { min }}=\frac{0,3 \sqrt{f_{c}} b_{w} s}{f_{f v}}$ :

$$
V_{c}=\left(\frac{130}{1000+d}\right) \lambda \phi_{c} \sqrt{f_{c}^{\prime}} b_{\mathrm{w}} d \geq 0,08 \lambda \phi_{c} \sqrt{f_{c}^{\prime}} b_{\mathrm{w}} d
$$

trong đó: $\phi_{c}$ là hệ số kháng cắt của bê tông; $\lambda$ là hệ số phụ thuộc vào trọng lượng riêng của bê tông; $\phi_{f}$ là hệ số kháng cắt cốt đai thanh FRP; $\mathrm{V}_{\mathrm{sF}}$ là khả năng chịu cắt của cốt đai thanh $\mathrm{FRP} ; \mathrm{V}_{\mathrm{ss}}$ là khả năng chịu cắt của cốt đai thép. 
Bảng 1.

Kết quả tính toán theo ACI440.1R-06.

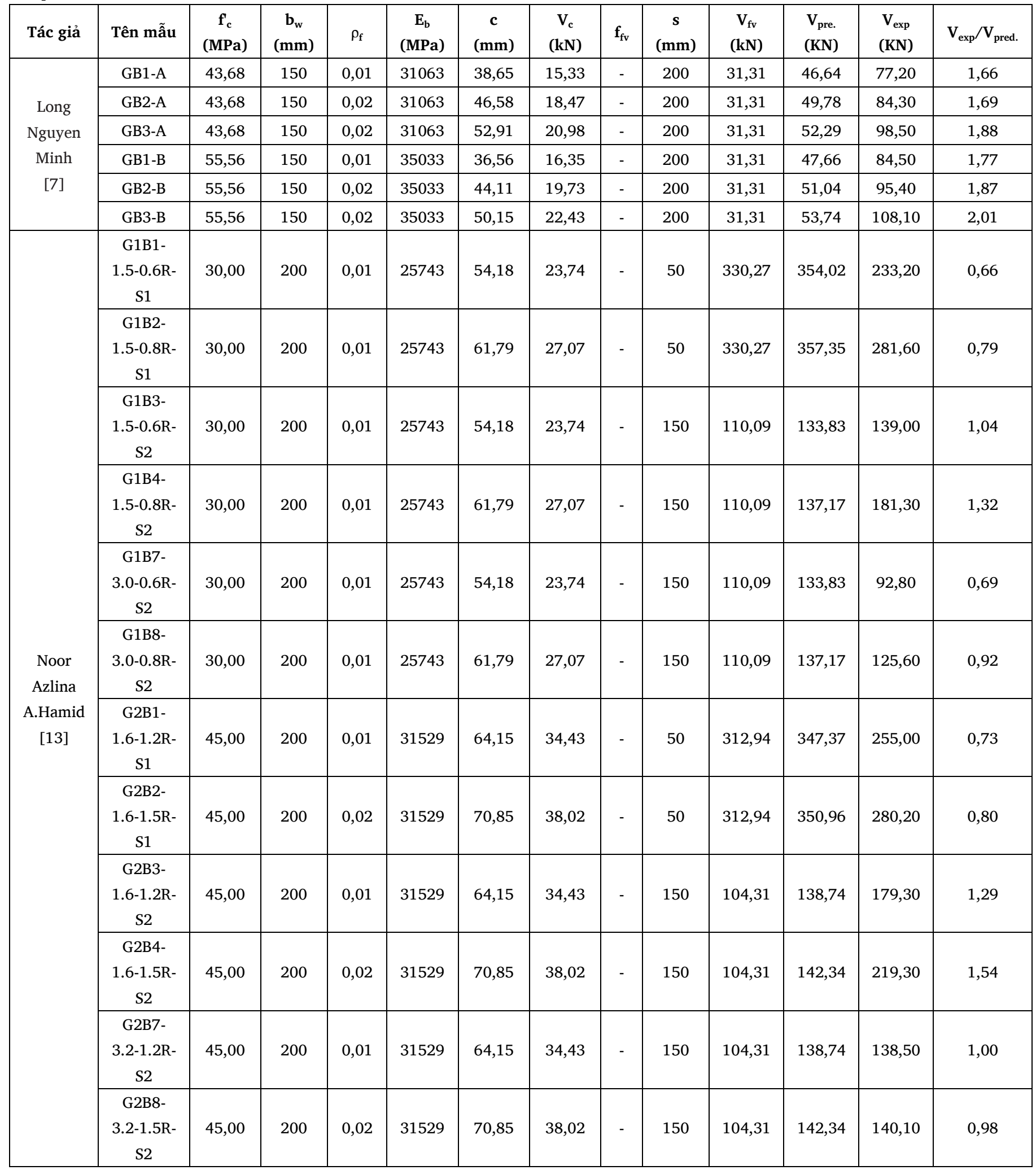


Bảng 1 (tiếp).

Kết quả tính toán theo ACI440.1R-06.

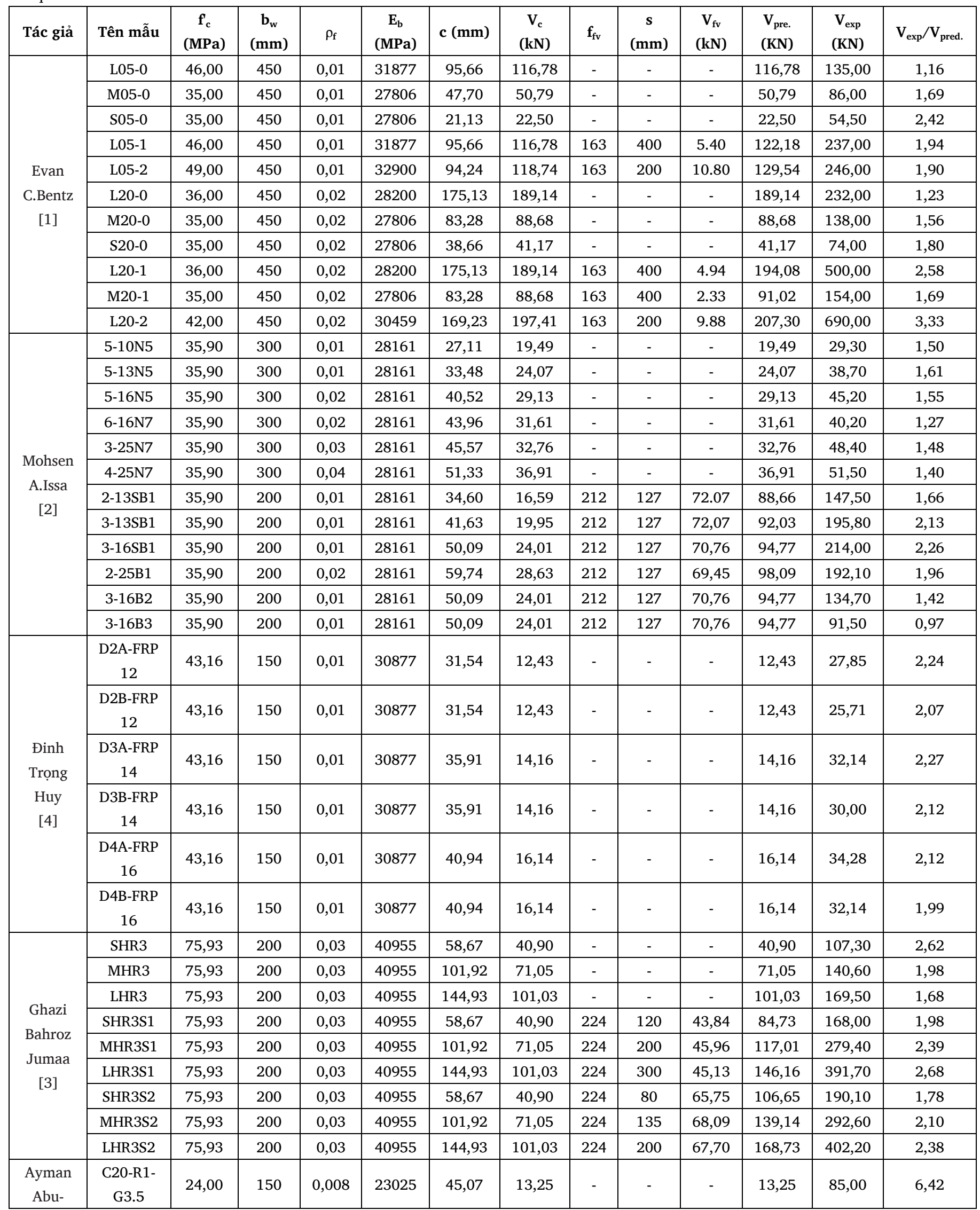




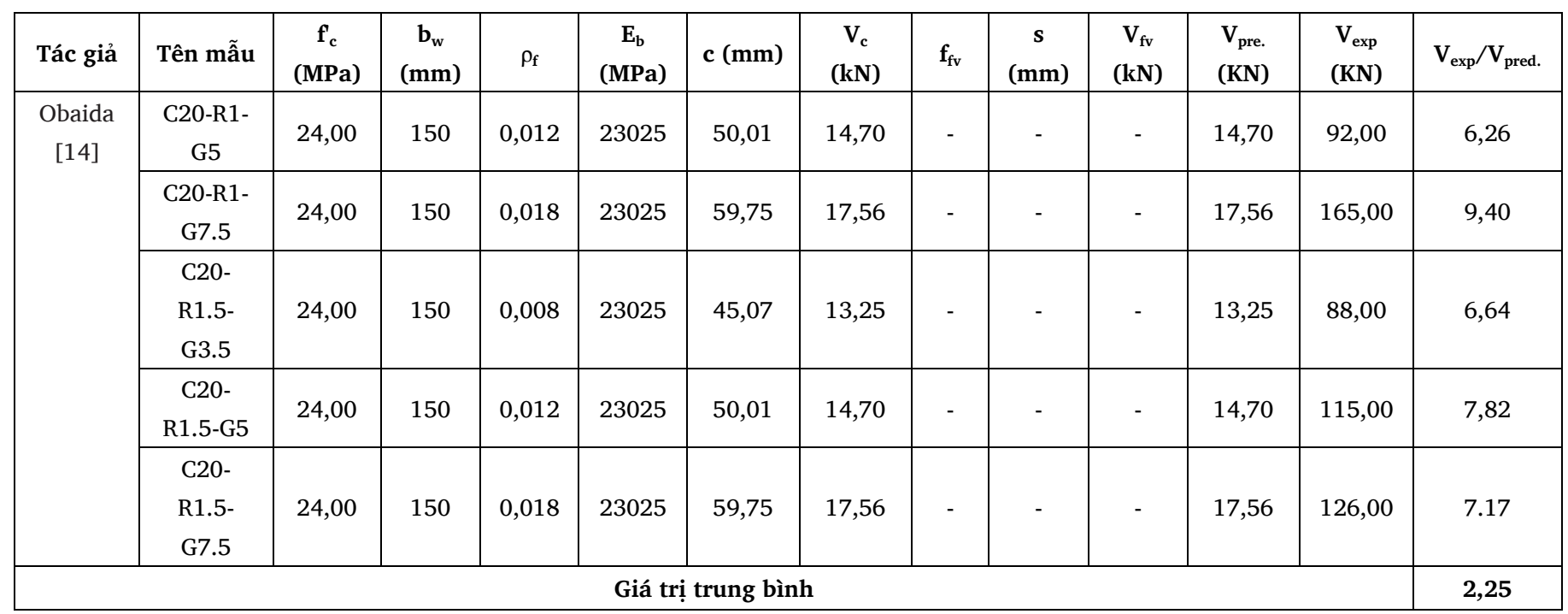

\section{Bảng 2.}

Kết quả tính toán theo CSA S806-02.

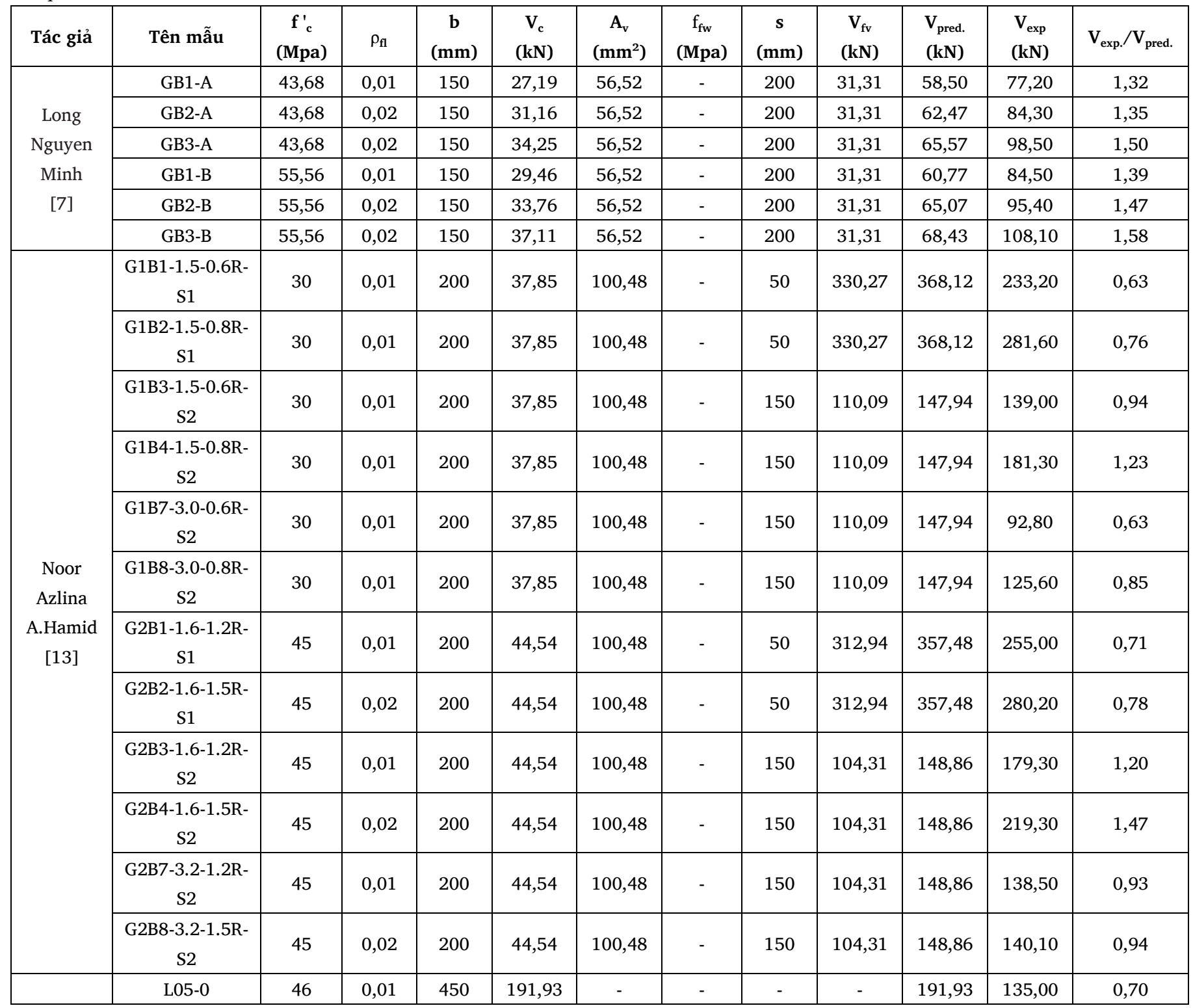




\begin{tabular}{|c|c|c|c|c|c|c|c|c|c|c|c|c|}
\hline Tác giả & Tên mẫu & $\begin{array}{c}f_{c}^{\prime} \\
(\mathrm{Mpa})\end{array}$ & $\rho_{\mathrm{fl}}$ & $\begin{array}{c}\mathrm{b} \\
(\mathrm{mm})\end{array}$ & $\begin{array}{c}\mathrm{V}_{\mathrm{c}} \\
(\mathrm{kN})\end{array}$ & $\begin{array}{c}\mathbf{A}_{v} \\
\left(\mathrm{~mm}^{2}\right)\end{array}$ & $\begin{array}{c}\mathrm{f}_{\mathrm{fw}} \\
\text { (Mpa) }\end{array}$ & $\begin{array}{c}\mathrm{s} \\
(\mathrm{mm})\end{array}$ & $\begin{array}{c}V_{\text {fv }} \\
(k N)\end{array}$ & $\begin{array}{l}\mathrm{V}_{\text {pred. }} \\
(\mathrm{kN})\end{array}$ & $\begin{array}{c}V_{\text {exp }} \\
(k N)\end{array}$ & $\mathrm{V}_{\text {exp. }} / \mathrm{V}_{\text {pred. }}$ \\
\hline \multirow{7}{*}{$\begin{array}{c}\text { Evan } \\
\text { C.Bentz } \\
{[1]}\end{array}$} & M05-0 & 35 & 0,01 & 450 & 105,42 & - & - & - & - & 105,42 & 86,00 & 0,82 \\
\hline & L05-1 & 46 & 0,01 & 450 & 191,93 & 14,13 & 204 & 400 & 2,03 & 193,96 & 237,00 & 1,22 \\
\hline & L05-2 & 49 & 0,01 & 450 & 198,09 & 14,13 & 204 & 200 & 4,05 & 202,14 & 246,00 & 1,22 \\
\hline & S20-0 & 35 & 0,02 & 450 & 54,95 & - & - & - & - & 54,95 & 74,00 & 1,35 \\
\hline & L20-1 & 36 & 0,02 & 450 & 161,99 & 14,13 & 204 & 400 & 1,85 & 163,84 & 500,00 & 3,05 \\
\hline & M20-1 & 35 & 0,02 & 450 & 99,76 & 14,13 & 204 & 400 & 0,88 & 100,64 & 154,00 & 1,53 \\
\hline & L20-2 & 42 & 0,02 & 450 & 174,96 & 14,13 & 204 & 200 & 3,71 & 178,67 & 690,00 & 3,86 \\
\hline \multirow{9}{*}{$\begin{array}{c}\text { Mohsen } \\
\text { A.Issa } \\
{[2]}\end{array}$} & 6-16N7 & 35,9 & 0,02 & 300 & 33,34 & - & - & - & - & 33,34 & 40,20 & 1,21 \\
\hline & $3-25 N 7$ & 35,9 & 0,03 & 300 & 34,08 & - & - & - & - & 34,08 & 48,40 & 1,42 \\
\hline & $4-25 N 7$ & 35,9 & 0,04 & 300 & 37,51 & - & - & - & - & 37,51 & 51,50 & 1,37 \\
\hline & 2-13SB1 & 35,9 & 0,01 & 200 & 35,18 & 157,00 & 265 & 127 & 27,03 & 62,21 & 147,50 & 2,37 \\
\hline & 3-13SB1 & 35,9 & 0,01 & 200 & 40,19 & 157,00 & 265 & 127 & 27,03 & 67,21 & 195,80 & 2,91 \\
\hline & 3-16SB1 & 35,9 & 0,01 & 200 & 45,81 & 157,00 & 265 & 127 & 26,54 & 72,35 & 214,00 & 2,96 \\
\hline & 2-25B1 & 35,9 & 0,02 & 200 & 52,06 & 157,00 & 265 & 127 & 26,04 & 78,11 & 192,10 & 2,46 \\
\hline & 3-16B2 & 35,9 & 0,01 & 200 & 38,64 & 157,00 & 265 & 127 & 26,54 & 65,17 & 134,70 & 2,07 \\
\hline & 3-16B3 & 35,9 & 0,01 & 200 & 34,54 & 157,00 & 265 & 127 & 26,54 & 61,07 & 91,50 & 1,50 \\
\hline
\end{tabular}

Bảng 2 (tiếp).

Kết quả tính toán theo CSA S806-02.

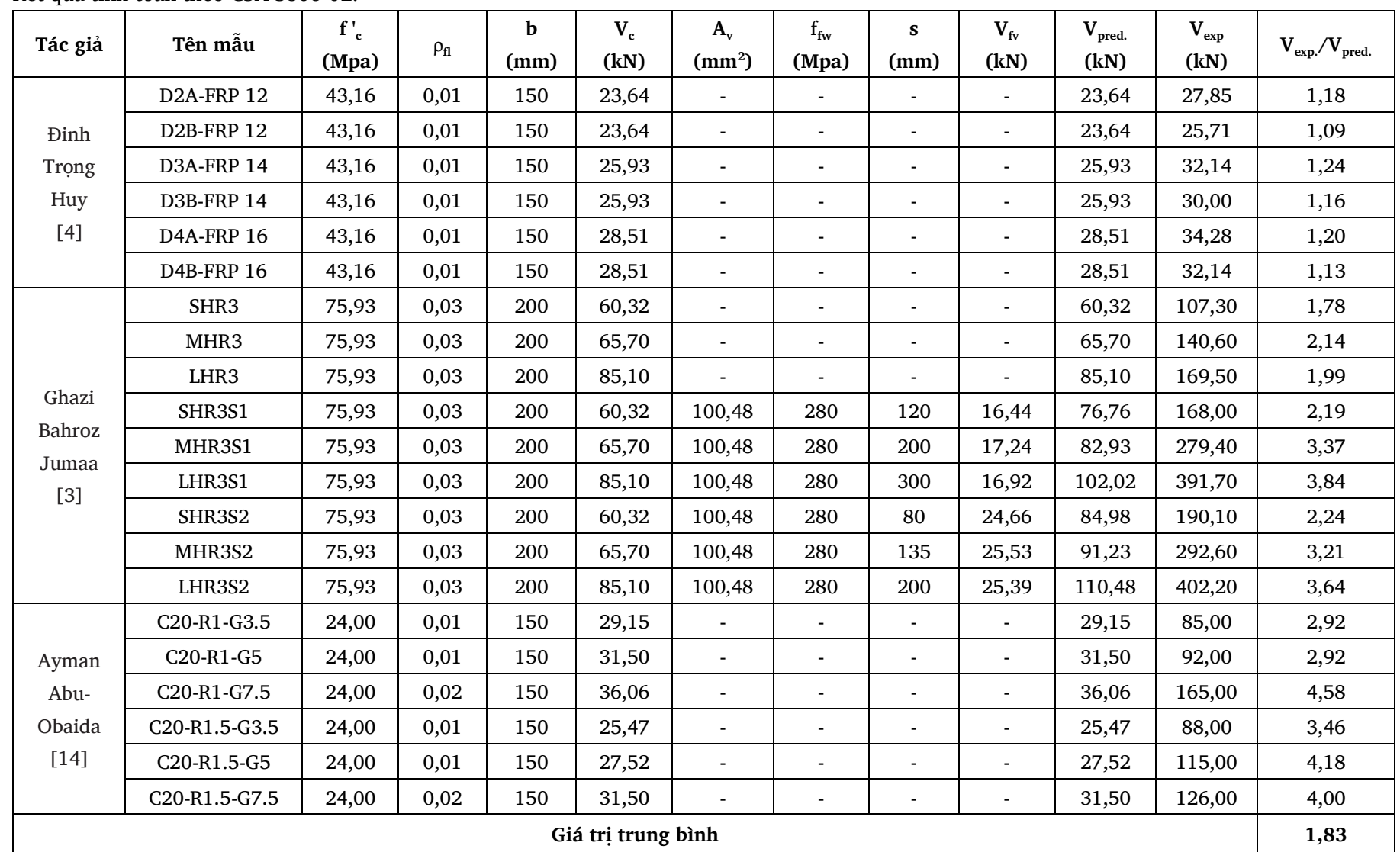


Bảng 3.

Kết quả tính toán theo JSCE-1997.

\begin{tabular}{|c|c|c|c|c|c|c|c|c|c|c|c|c|}
\hline Tác giả & Tên mẫu & $\begin{array}{c}\mathbf{f}_{\mathbf{c}} \\
(\mathbf{M p a})\end{array}$ & $\begin{array}{c}b_{w} \\
(\mathrm{~mm})\end{array}$ & $\rho_{\mathrm{f}}$ & $\mathbf{f}_{\mathrm{vud}}$ & $\begin{array}{c}\mathrm{V}_{\mathrm{c}} \\
(\mathrm{kN})\end{array}$ & $\begin{array}{c}A_{f v} \\
\left(\mathrm{~mm}^{2}\right)\end{array}$ & $\varepsilon_{\mathrm{fv}}$ & $\begin{array}{c}\mathrm{V}_{\mathrm{fv}} \\
(\mathrm{kN})\end{array}$ & $\begin{array}{l}\mathrm{V}_{\text {pred. }} \\
(\mathrm{KN})\end{array}$ & $\begin{array}{l}\mathrm{V}_{\text {exp. }} \\
(\mathrm{KN})\end{array}$ & $\mathrm{V}_{\text {exp. }} / \mathrm{V}_{\text {pred. }}$ \\
\hline \multirow{6}{*}{$\begin{array}{c}\text { Long } \\
\text { Nguyen } \\
\text { Minh } \\
\text { [7] }\end{array}$} & GB1-A & 43,7 & 150 & 0,01 & 0,70 & 22,57 & 56,52 & - & 24,75 & 47,32 & 77,20 & 1,63 \\
\hline & GB2-A & 43,7 & 150 & 0,02 & 0,70 & 25,86 & 56,52 & - & 24,75 & 50,61 & 84,30 & 1,67 \\
\hline & GB3-A & 43,7 & 150 & 0,02 & 0,70 & 28,43 & 56,52 & - & 24,75 & 53,18 & 98,50 & 1,85 \\
\hline & GB1-B & 55,6 & 150 & 0,01 & 0,76 & 23,07 & 56,52 & - & 24,75 & 47,82 & 84,50 & 1,77 \\
\hline & GB2-B & 55,6 & 150 & 0,02 & 0,76 & 26,44 & 56,52 & - & 24,75 & 51,19 & 95,40 & 1,86 \\
\hline & GB3-B & 55,6 & 150 & 0,02 & 0,76 & 29,06 & 56,52 & - & 24,75 & 53,82 & 108,10 & 2,01 \\
\hline \multirow{12}{*}{$\begin{array}{c}\text { Noor } \\
\text { Azlina } \\
\text { A.Hamid } \\
\text { [13] }\end{array}$} & $\begin{array}{c}\text { G1B1-1.5-0.6R- } \\
\text { S1 }\end{array}$ & 30,0 & 200 & 0,01 & 0,62 & 32,11 & 100,48 & - & 261,09 & 293,19 & 233,20 & 0,80 \\
\hline & $\begin{array}{c}\text { G1B2-1.5-0.8R- } \\
\text { S1 }\end{array}$ & 30,0 & 200 & 0,01 & 0,62 & 35,34 & 100,48 & - & 261,09 & 296,42 & 281,60 & 0,95 \\
\hline & $\begin{array}{c}\text { G1B3-1.5-0.6R- } \\
\text { S2 }\end{array}$ & 30,0 & 200 & 0,01 & 0,62 & 32,11 & 100,48 & - & 87,03 & 119,13 & 139,00 & 1,17 \\
\hline & $\begin{array}{c}\text { G1B4-1.5-0.8R- } \\
\text { S2 }\end{array}$ & 30,0 & 200 & 0,01 & 0,62 & 35,34 & 100,48 & - & 87,03 & 122,37 & 181,30 & 1,48 \\
\hline & $\begin{array}{c}\text { G1B7-3.0-0.6R- } \\
\text { S2 }\end{array}$ & 30,0 & 200 & 0,01 & 0,62 & 32,11 & 100,48 & - & 87,03 & 119,13 & 92,80 & 0,78 \\
\hline & $\begin{array}{c}\text { G1B8-3.0-0.8R- } \\
\text { S2 } \\
\end{array}$ & 30,0 & 200 & 0,01 & 0,62 & 35,34 & 100,48 & - & 87,03 & 122,37 & 125,60 & 1,03 \\
\hline & $\begin{array}{c}\text { G2B1-1.6-1.2R- } \\
\text { S1 }\end{array}$ & 45,0 & 200 & 0,01 & 0,71 & 44,47 & 100,48 & - & 247,38 & 291,85 & 255,00 & 0,87 \\
\hline & $\begin{array}{c}\text { G2B2-1.6-1.5R- } \\
\text { S1 } \\
\end{array}$ & 45,0 & 200 & 0,02 & 0,71 & 47,90 & 100,48 & - & 247,38 & 295,29 & 280,20 & 0,95 \\
\hline & $\begin{array}{c}\text { G2B3-1.6-1.2R- } \\
\text { S2 }\end{array}$ & 45,0 & 200 & 0,01 & 0,71 & 44,47 & 100,48 & - & 82,46 & 126,93 & 179,30 & 1,41 \\
\hline & $\begin{array}{c}\text { G2B4-1.6-1.5R- } \\
\text { S2 }\end{array}$ & 45,0 & 200 & 0,02 & 0,71 & 47,90 & 100,48 & - & 82,46 & 130,36 & 219,30 & 1,68 \\
\hline & $\begin{array}{c}\text { G2B7-3.2-1.2R- } \\
\text { S2 } \\
\end{array}$ & 45,0 & 200 & 0,01 & 0,71 & 44,47 & 100,48 & - & 82,46 & 126,93 & 138,50 & 1,09 \\
\hline & $\begin{array}{c}\text { G2B8-3.2-1.5R- } \\
\text { S2 }\end{array}$ & 45,0 & 200 & 0,02 & 0,71 & 47,90 & 100,48 & - & 82,46 & 130,36 & 140,10 & 1,07 \\
\hline
\end{tabular}

Bảng 3 (tiếp).

Kết quả tính toán theo JSCE-1997.

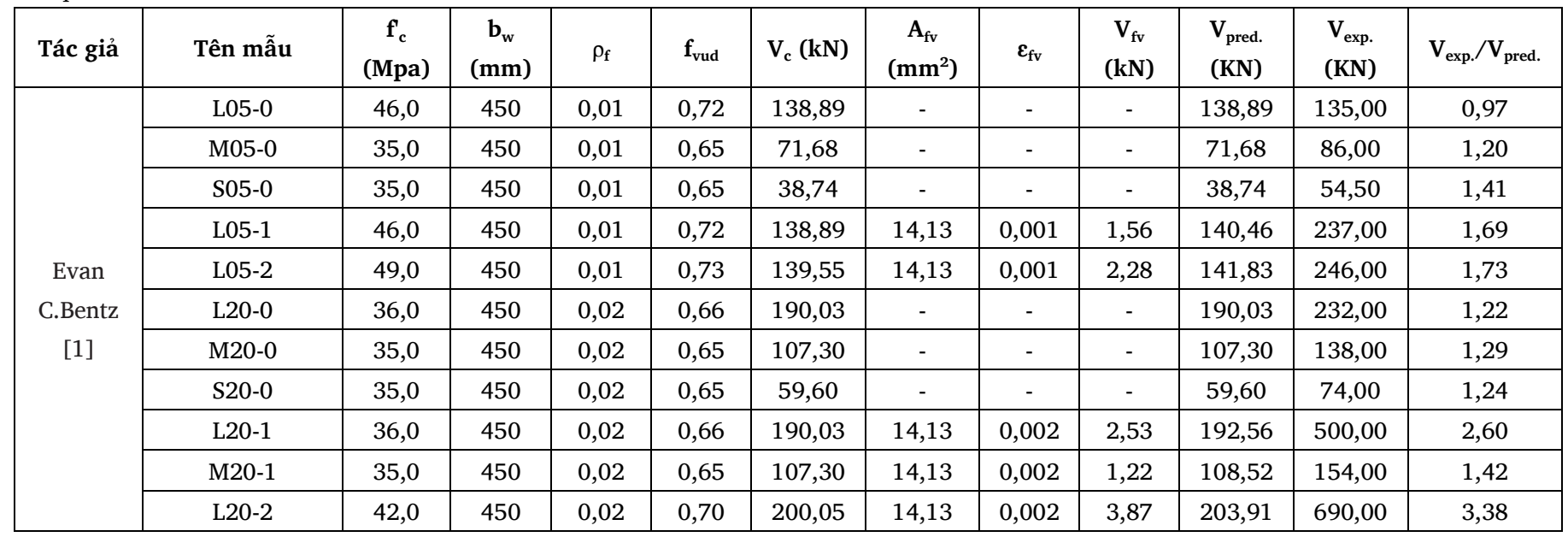




\begin{tabular}{|c|c|c|c|c|c|c|c|c|c|c|c|c|}
\hline Tác giả & Tên mẫu & $\begin{array}{c}\mathbf{f}_{\mathbf{c}} \\
(\mathrm{Mpa})\end{array}$ & $\begin{array}{c}b_{w} \\
(\mathrm{~mm})\end{array}$ & $\rho_{\mathrm{f}}$ & $\mathbf{f}_{\mathrm{vud}}$ & $\mathrm{V}_{\mathrm{c}}(\mathrm{kN})$ & $\begin{array}{c}A_{\mathrm{fv}} \\
\left(\mathrm{mm}^{2}\right)\end{array}$ & $\varepsilon_{\mathrm{fv}}$ & $\begin{array}{c}\mathrm{V}_{\mathrm{fv}} \\
(\mathrm{kN})\end{array}$ & $\begin{array}{l}\mathrm{V}_{\text {pred. }} \\
(\mathrm{KN})\end{array}$ & $\begin{array}{l}\mathrm{V}_{\text {exp. }} \\
\text { (KN) }\end{array}$ & $\mathrm{V}_{\text {exp. }} / \mathrm{V}_{\text {pred. }}$ \\
\hline \multirow{7}{*}{$\begin{array}{c}\text { Mohsen } \\
\text { A.Issa } \\
\text { [2] }\end{array}$} & 5-10N5 & 35,9 & 300 & 0,01 & 0,66 & 30,14 & - & - & - & 30,14 & 29,30 & 0,97 \\
\hline & 5-16N5 & 35,9 & 300 & 0,02 & 0,66 & 40,72 & - & - & - & 40,72 & 45,20 & 1,11 \\
\hline & $6-16 N 7$ & 35,9 & 300 & 0,02 & 0,66 & 43,38 & - & - & - & 43,38 & 40,20 & 0,93 \\
\hline & 2-13SB1 & 35,9 & 200 & 0,01 & 0,66 & 25,22 & 157,00 & 0,002 & 24,79 & 50,01 & 147,50 & 2,95 \\
\hline & 3-13SB1 & 35,9 & 200 & 0,01 & 0,66 & 28,81 & 157,00 & 0,002 & 30,27 & 59,08 & 195,80 & 3,31 \\
\hline & 3-16SB1 & 35,9 & 200 & 0,01 & 0,66 & 32,99 & 157,00 & 0,002 & 37,18 & 70,18 & 214,00 & 3,05 \\
\hline & 2-25B1 & 35,9 & 200 & 0,02 & 0,66 & 37,67 & 157,00 & 0,003 & 45,47 & 83,14 & 192,10 & 2,31 \\
\hline \multirow{5}{*}{$\begin{array}{c}\text { Đinh } \\
\text { Trọng } \\
\text { Huy } \\
\text { [4] }\end{array}$} & D2B-FRP 12 & 43,2 & 150 & 0,01 & 0,70 & 19,40 & - & - & - & 19,40 & 25,71 & 1,33 \\
\hline & D3A-FRP 14 & 43,2 & 150 & 0,01 & 0,70 & 21,29 & - & - & - & 21,29 & 32,14 & 1,51 \\
\hline & D3B-FRP 14 & 43,2 & 150 & 0,01 & 0,70 & 21,29 & - & - & - & 21,29 & 30,00 & 1,41 \\
\hline & D4A-FRP 16 & 43,2 & 150 & 0,01 & 0,70 & 23,40 & - & - & - & 23,40 & 34,28 & 1,46 \\
\hline & D4B-FRP 16 & 43,2 & 150 & 0,01 & 0,70 & 23,40 & - & - & - & 23,40 & 32,14 & 1,37 \\
\hline \multirow{5}{*}{$\begin{array}{c}\text { Ghazi } \\
\text { Bahroz } \\
\text { Jumaa } \\
\text { [3] }\end{array}$} & SHR3 & 75,9 & 200 & 0,03 & 0,85 & 46,05 & - & - & - & 46,05 & 107,30 & 2,33 \\
\hline & MHR3 & 75,9 & 200 & 0,03 & 0,85 & 69,68 & - & - & - & 69,68 & 140,60 & 2,02 \\
\hline & LHR3 & 75,9 & 200 & 0,03 & 0,85 & 90,66 & - & - & - & 90,66 & 169,50 & 1,87 \\
\hline & SHR3S1 & 75,9 & 200 & 0,03 & 0,85 & 46,05 & 100,48 & 0,002 & 21,27 & 67,33 & 168,00 & 2,50 \\
\hline & MHR3S1 & 75,9 & 200 & 0,03 & 0,85 & 69,68 & 100,48 & 0,003 & 27,99 & 97,67 & 279,40 & 2,86 \\
\hline \multirow{4}{*}{$\begin{array}{c}\text { Ayman } \\
\text { Abu- } \\
\text { Obaida } \\
\text { [14] }\end{array}$} & C20-R1-G7.5 & 24,0 & 150 & 0,02 & 0,58 & 23,13 & - & - & - & 23,13 & 165,00 & 7,13 \\
\hline & C20-R1.5-G3.5 & 24,0 & 150 & 0,01 & 0,58 & 18,70 & - & - & - & 18,70 & 88,00 & 4,71 \\
\hline & C20-R1.5-G5 & 24,0 & 150 & 0,01 & 0,58 & 20,20 & - & - & - & 20,20 & 115,00 & 5,69 \\
\hline & C20-R1.5-G7.5 & 24,0 & 150 & 0,018 & 0,58 & 23,128 & - & - & - & 23,13 & 126,00 & 5,45 \\
\hline \multicolumn{12}{|c|}{ Giá trị trung bình } & 2,05 \\
\hline
\end{tabular}

\subsection{Tiêu chuẩn Nhật Bản JSCE-1997 [11]}

Khả năng chịu cắt của bê tông được xác định:

$$
V_{c}=\frac{\beta_{d} \beta_{p} \beta_{n} f_{v u d} b_{w} d}{\gamma_{b}}
$$

Khả năng chịu cắt của cốt đai thanh FRP được xác định:

$$
V_{f v}=\left[\frac{A_{f v} E_{f v} \varepsilon_{f v}\left(\sin \alpha_{s}+\cos \alpha_{s}\right)}{s} z\right] / \gamma_{b} \leq \frac{f_{f b}}{E_{f v}} b_{w} d
$$

trong đó: $\beta_{d}, \beta_{p}$ là các hệ số phụ thuộc vật liệu và tiết diện; $\beta_{n}$ là hệ số tính đến lực dọc trục; $\gamma_{b}$ là hệ số giảm ứng suất; $\alpha_{s}$ là góc nghiêng của cốt đai so với trục dầm; $E_{f v}$ là môđun đàn hồi của cốt đai thanh FRP; $f_{\text {vud }}$ và $\varepsilon_{f v}$ được xác định theo công thức:

$$
f_{\text {vud }}=0.2 f_{c}^{\frac{1}{3}} \leq 0,72(M P a)
$$

$$
\varepsilon_{f V}=0,0001 \sqrt{f_{\text {mad }} \frac{\rho_{\rho} E_{f}}{\rho_{f v} E_{f v}}}\left[1+2\left(\frac{\delta_{N}}{f_{m c d}}\right)\right] \leq \frac{f_{f o}}{E_{f v}}
$$

Cường độ chịu nén của bê tông kể đến hiệu ứng kích cỡ:

$$
f_{m c d}^{\prime}=\left(\frac{h}{100}\right)^{-1 / 10} f_{c}^{\prime}
$$

\section{3. Đánh giá công thức thiết kế trong một số tiêu chuẩn}

Một bộ dữ liệu thực nghiệm được thu thập bao gồm kết quả của 73 dầm bê tông cốt dọc thanh FRP, không có cốt đai, có cốt đai thanh FRP hoặc cốt đai thép thường. Nhóm dầm sử dụng cốt thanh GFRP và BFRP được đưa vào cùng nhóm vì cường độ chịu kéo và môđun đàn hồi của 2 loại cốt này không chênh lệch nhau nhiều. Phạm vi thay đổi của các thông số dầm tóm tắt như sau: 
Bảng 4.

So sánh kết quả tính toán giữa các tiêu chuẩn với kết quả thực nghiệm dầm cốt thanh GFRP, BFRP.

\begin{tabular}{|c|c|c|c|c|}
\hline \multirow{2}{*}{ Tiêu chuẩn } & \multicolumn{4}{|c|}{$\mathrm{V}_{\text {exp }} / \mathrm{V}_{\text {pred. }}$} \\
\cline { 2 - 5 } & $\overline{\mathrm{X}}$ & $\mathrm{SD}$ & $\mathrm{CoV}$ & $\mathrm{AAE}$ \\
\hline ACI440.1R-06 & 2,25 & 1,78 & 0,8 & 71,8 \\
\hline CSA S806-02 & 1,83 & 1,02 & 0,56 & 73,08 \\
\hline JSCE-1997 & 2,05 & 1,32 & 0,64 & 69,8 \\
\hline
\end{tabular}

\section{Bảng 5.}

Kết quả tính toán theo ACI440.1R-06.

\begin{tabular}{|c|c|c|c|c|c|c|c|c|c|c|c|c|c|}
\hline Tác giả & Tên mẫu & $\begin{array}{c}\mathbf{f}_{\mathrm{c}} \\
(\mathrm{MPa})\end{array}$ & $\begin{array}{c}\mathbf{b}_{\mathrm{w}} \\
(\mathrm{mm})\end{array}$ & $\rho_{\mathrm{f}}$ & $\begin{array}{c}\mathrm{E}_{\mathrm{b}} \\
(\mathrm{MPa})\end{array}$ & $\begin{array}{c}c \\
(\mathrm{~mm})\end{array}$ & $\begin{array}{c}V_{c} \\
(k N)\end{array}$ & $\mathbf{f}_{\mathrm{fv}}$ & $\begin{array}{c}\mathrm{s} \\
(\mathrm{mm})\end{array}$ & $\begin{array}{c}V_{\mathrm{fv}} \\
(\mathrm{kN})\end{array}$ & $\begin{array}{l}\mathrm{V}_{\text {pre. }} \\
(\mathrm{KN})\end{array}$ & $\begin{array}{l}\mathrm{V}_{\text {exp }} \\
(\mathrm{KN})\end{array}$ & $\mathrm{V}_{\text {exp }} / \mathrm{V}_{\text {pred. }}$ \\
\hline \multirow{4}{*}{$\begin{array}{c}\text { A.Ghani } \\
\text { Razaqpur } \\
\text { [5] }\end{array}$} & BR1 & 40,50 & 200 & 0,003 & 29911 & 32,41 & 16,50 & - & - & - & 16,50 & 36,11 & 2,19 \\
\hline & BR3 & 40,50 & 200 & 0,006 & 29911 & 49,16 & 25,03 & - & - & - & 25,03 & 47,23 & 1,89 \\
\hline & BR4 & 40,50 & 200 & 0,009 & 29911 & 56,82 & 28,93 & - & - & - & 28,93 & 42,71 & 1,48 \\
\hline & BA4 & 40,50 & 200 & 0,005 & 29911 & 44,39 & 22,60 & - & - & - & 22,60 & 38,45 & 1,70 \\
\hline \multirow{3}{*}{$\begin{array}{c}\text { Ashraf F. } \\
\text { Ashour } \\
{[15]}\end{array}$} & B-400-2 & 37,09 & 200 & 0,001 & 28623 & 38,39 & 18,71 & - & - & - & 18,71 & 65,76 & 3,52 \\
\hline & B-400-4 & 37,09 & 200 & 0,002 & 28623 & 53,00 & 25,82 & - & - & - & 25,82 & 72,23 & 2,80 \\
\hline & B-300-2 & 48,08 & 200 & 0,002 & 32589 & 30,67 & 17,01 & - & - & - & 17,01 & 65,76 & 3,87 \\
\hline
\end{tabular}

\section{Bảng 6.}

Kết quả tính toán theo CSA S806-02.

\begin{tabular}{|c|c|c|c|c|c|c|c|c|c|c|c|c|}
\hline Tác giả & Tên mẫu & $\begin{array}{c}\mathbf{f}_{c}^{\prime} \\
(\mathrm{Mpa})\end{array}$ & $\rho_{\mathrm{fl}}$ & $\begin{array}{c}\mathbf{b} \\
(\mathrm{mm})\end{array}$ & $\begin{array}{c}\mathrm{V}_{\mathrm{c}} \\
(\mathrm{kN})\end{array}$ & $\begin{array}{c}A_{v} \\
\left(\mathrm{~mm}^{2}\right)\end{array}$ & $\begin{array}{c}\mathrm{f}_{\mathrm{fw}} \\
\text { (Mpa) }\end{array}$ & $\begin{array}{c}\mathrm{s} \\
(\mathrm{mm})\end{array}$ & $\begin{array}{c}V_{\mathrm{fv}} \\
(\mathrm{kN})\end{array}$ & $\begin{array}{l}\mathrm{V}_{\text {pred. }} \\
(\mathrm{kN})\end{array}$ & $\begin{array}{c}V_{\text {exp }} \\
(k N)\end{array}$ & $\mathrm{V}_{\text {exp }} / \mathrm{V}_{\text {pred. }}$ \\
\hline \multirow{4}{*}{$\begin{array}{c}\text { A.Ghani } \\
\text { Razaqpur } \\
{[5]}\end{array}$} & BR1 & 40,5 & 0,003 & 200 & 27,80 & - & - & - & - & 27,80 & 36,11 & 1,30 \\
\hline & BR3 & 40,5 & 0,006 & 200 & 37,83 & - & - & - & - & 37,83 & 47,23 & 1,25 \\
\hline & BR4 & 40,5 & 0,009 & 200 & 42,29 & - & - & - & - & 42,29 & 42,71 & 1,01 \\
\hline & BA4 & 40,5 & 0,005 & 200 & 29,43 & - & - & - & - & 29,43 & 38,45 & 1,31 \\
\hline \multirow{3}{*}{$\begin{array}{c}\text { Ashraf F. } \\
\text { Ashour } \\
\text { [15] }\end{array}$} & B-400-2 & 37,09 & 0,001 & 200 & 34,66 & - & - & - & - & 34,66 & 65,76 & 1,90 \\
\hline & B-400-4 & 37,09 & 0,002 & 200 & 43,60 & - & - & - & - & 43,60 & 72,23 & 1,66 \\
\hline & B-300-2 & 48,08 & 0,002 & 200 & 27,93 & - & - & - & - & 27,93 & 65,76 & 2,35 \\
\hline
\end{tabular}

\section{Bảng 7.}

Kết quả tính toán theo JSCE-1997.

\begin{tabular}{|c|c|c|c|c|c|c|c|c|c|c|c|c|}
\hline Tác giả & Tên mẫu & $\begin{array}{c}\mathbf{f}_{c} \\
(\mathbf{M p a})\end{array}$ & $\begin{array}{c}b_{w} \\
(\mathrm{~mm})\end{array}$ & $\rho_{\mathrm{f}}$ & $\mathbf{f}_{\mathrm{vud}}$ & $\mathrm{V}_{\mathrm{c}}(\mathrm{kN})$ & $\begin{array}{c}A_{\mathrm{fv}} \\
\left(\mathrm{mm}^{2}\right)\end{array}$ & $\varepsilon_{\mathrm{fv}}$ & $\begin{array}{c}\mathrm{V}_{\mathrm{fv}} \\
(\mathrm{kN})\end{array}$ & $\begin{array}{l}\mathrm{V}_{\text {pred. }} \\
(\mathrm{KN})\end{array}$ & $\begin{array}{l}V_{\text {exp. }} \\
(K N)\end{array}$ & $\mathrm{V}_{\text {exp }} / \mathrm{V}_{\text {pred. }}$ \\
\hline \multirow{3}{*}{$\begin{array}{c}\text { A.Ghani } \\
\text { Razaqpur } \\
{[5]}\end{array}$} & BR1 & 40,5 & 200 & 0,003 & 0,69 & 25,40 & - & - & - & 25,40 & 36,11 & 1,42 \\
\hline & BR3 & 40,5 & 200 & 0,006 & 0,69 & 34,56 & - & - & - & 34,56 & 47,23 & 1,37 \\
\hline & BR4 & 40,5 & 200 & 0,009 & 0,69 & 38,63 & - & - & - & 38,63 & 42,71 & 1,11 \\
\hline
\end{tabular}




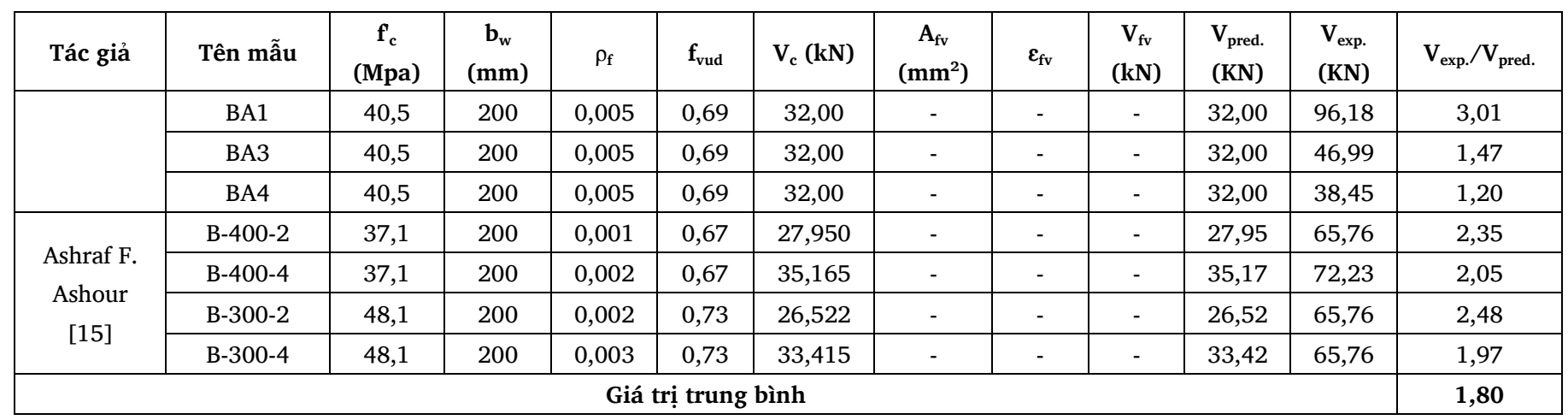

- Bề rộng dầm $b=150 \div 450 \mathrm{~mm}$;

- Chiều cao dầm $h=250 \div 1000 \mathrm{~mm}$;

- Tỷ lệ nhịp chịu cắt/chiều cao làm việc $a / d=1 \div 7$;

- Cường độ chịu nén bê tông mẫu trụ $f_{c}^{\prime}=24 \div 75 \mathrm{MPa}$;

- Hàm lượng cốt dọc thanh FRP $\rho_{f}=0,5 \div 4(\%)$;

- Môđun đàn hồi cốt thanh FRP $E_{f}=37000 \div 145000 \mathrm{MPa}$;

Các kết quả tính toán khả năng chịu cắt theo các tiêu chuẩn trên được so sánh với các kết quả thực nghiệm tương ứng nên các hệ số giảm độ bền, hệ số kháng cắt, hệ số giảm ứng suất đều lấy bằng 1,0. Các giá trị cường độ vật liệu đưa vào tính toán được lấy như các giá trị thí nghiệm vật liệu công bố trong các tài liệu tương ứng.

\subsection{Dầm sử dụng cốt thanh GFRP, BFRP}

Các nghiên cứu thực nghiệm của Minh và cộng sự [7], Hamid và cộng sự [13], Bentz và cộng sự [1], Huy [4], Abu-Obaida và cộng sự [14] trên các dầm đặt cốt dọc loại thanh GFRP, cốt đai thép hoặc GFRP hoặc không có cốt đai trong nhịp chịu cắt, của Issa và cộng sự [2], Jumaa và Yousif [3] trên các dầm cốt dọc loại thanh BFRP, cốt đai BFRP hoặc không có cốt đai trong nhịp chịu cắt được tổng hợp với các thông số như trong Bảng 1 . Khả năng chịu cắt của dầm theo thực nghiệm, $\mathrm{V}_{\text {exp }}$, khả năng chịu cắt của dầm theo các tiêu chuẩn, $\mathrm{V}_{\text {pred }}$.

Để xác định tương quan giữa kết quả tính toán theo các tiêu chuẩn so với kết quả thực nghiệm, các giá trị như tỷ lệ trung bình $\mathrm{V}_{\text {exp }} / \mathrm{V}_{\text {pred }}(\overline{\mathrm{X}})$, độ lệch chuẩn (SD), hệ số biến động ( $\mathrm{CoV})$, sai số tuyệt đối trung bình (AAE) của tỷ lệ $\mathrm{V}_{\text {exp }}$. $/ \mathrm{V}_{\text {pred }}$ được so sánh trong Bảng 4 .

Từ Bảng 4 có thể thấy, tiêu chuẩn CSA S806-02 cho kết quả dự báo khả năng chịu cắt gần sát với kết quả thực nghiệm nhất vì các hệ số $\overline{\mathrm{X}}, \mathrm{SD}$ và $\mathrm{CoV}$ bé nhất. Tiêu chuẩn ACI440.1R-06 cho kết quả an toàn nhất khi 3 trên 4 thông số cho kết quả cao nhất. Ngoài ra, khi tính toán theo ACI440.1R-06 cho kết quả có tính biến động rất cao. Các kết quả ở các bảng 1, 2, 3 tính toán trên các dầm của Ayman Abu-Obaida và cộng sự [14] với tỷ lệ $\mathrm{a} / \mathrm{d}$ thay đổi từ 1 đến 1,5 cho thấy tỷ số trung bình $\mathrm{V}_{\text {exp }} / \mathrm{V}_{\text {pred }}=7,28$, cao hơn nhiều lần tỷ số trung bình $\mathrm{V}_{\text {exp }} / \mathrm{V}_{\text {pred }}$ cho toàn bộ bộ dữ liệu. Có thể giải thích lý do chính là vì tiêu chuẩn ACI440.1R-06 không tính đến ảnh hưởng của tỷ lệ a/d tới khả năng chịu cắt của dầm.

\subsection{Dầm sử dụng cốt thanh CFRP}

Các nghiên cứu thực nghiệm của Razaqpur và cộng sự [5], Ashour và cộng sự [15] trên các dầm đặt cốt dọc loại thanh CFRP, không có cốt đai trong nhịp chịu cắt được tổng như trong Bảng 5 . Khả năng chịu cắt của dầm theo thực nghiệm, $\mathrm{V}_{\text {exp }}$, khả năng chịu cắt của dầm theo các tiêu chuẩn, $\mathrm{V}_{\text {pred. }}$. Các kết quả tính toán khả năng chịu cắt theo các tiêu chuẩn được so sánh với các kết quả thực nghiệm tương ứng nên các hệ số giảm độ bền, hệ số kháng cắt, hệ số giảm ứng suất đều lấy bằng 1,0. Các giá trị cường độ vật liệu đưa vào tính toán được lấy như các giá trị thí nghiệm vật liệu công bố trong các tài liệu tương ứng.

Bảng 8.

So sánh kết quả tính toán giữa các tiêu chuẩn với kết quả thực nghiệm dầm cốt thanh CFRP.

\begin{tabular}{|c|c|c|c|c|}
\hline \multirow{2}{*}{ Tiêu chuẩn } & \multicolumn{4}{|c|}{$\mathrm{V}_{\text {exp. }} / \mathrm{V}_{\text {pred}} \cdot$} \\
\cline { 2 - 5 } & $\overline{\mathrm{X}}$ & $\mathrm{SD}$ & $\mathrm{CoV}$ & $\mathrm{AAE}$ \\
\hline ACI440.1R & 2,59 & 0,93 & 0,42 & 34,27 \\
\hline CSA S806-02 & 1,62 & 0,46 & 0,28 & 21,49 \\
\hline JSCE-1997 & 1,8 & 0,61 & 0,34 & 24,81 \\
\hline
\end{tabular}

Tương tự như khi tính toán cho dầm cốt thanh GFRP và BFRP, tiêu chuẩn CSA S806-02 cho kết quả tính toán gần sát với các kết quả thực nghiệm nhất. Tất cả 4 thông số so sánh của tiêu chuẩn ACI440.1R06 đều có giá trị lớn nhất (Bảng 8). Điều này một lần nữa chứng tỏ tiêu chuẩn ACI440.1R-06 cho kết quả an toàn nhất trong 3 tiêu chuẩn trên. So sánh Bảng 4 và Bảng 8 có thể thấy kết quả dự báo theo 3 tiêu chuẩn cho dầm cốt thanh GFRP và BFRP nói chung an toàn hơn so với dầm cốt thanh CFRP nhưng độ phân tán kết quả cao hơn.

Từ Hình 1 đến Hình 3 thể hiện một cách so sánh khác giữa kết quả tính toán theo 3 tiêu chuẩn với kết quả thực nghiệm trên toàn bộ các dầm bê tông cốt dọc FRP chịu cắt.

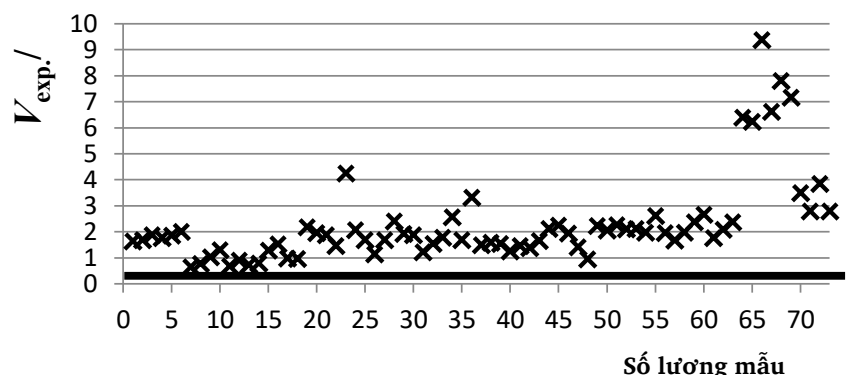

Hình 1. Tỷ lệ $\mathrm{V}_{\text {exp }} / \mathrm{V}_{\text {pred }}$. theo tiêu chuẩn ACI440.1R. 


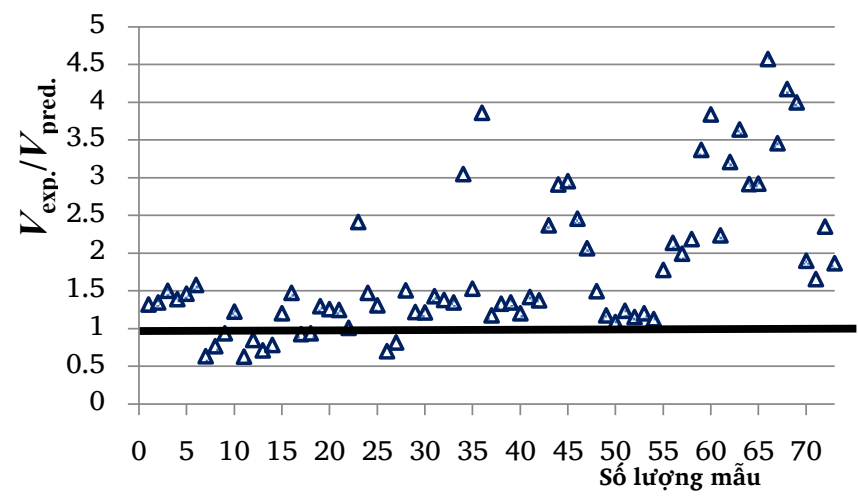

Hình 2. Tỷ lệ $\mathrm{V}_{\text {exp }} / \mathrm{V}_{\text {pred }}$ theo tiêu chuẩn CSA S806-02.

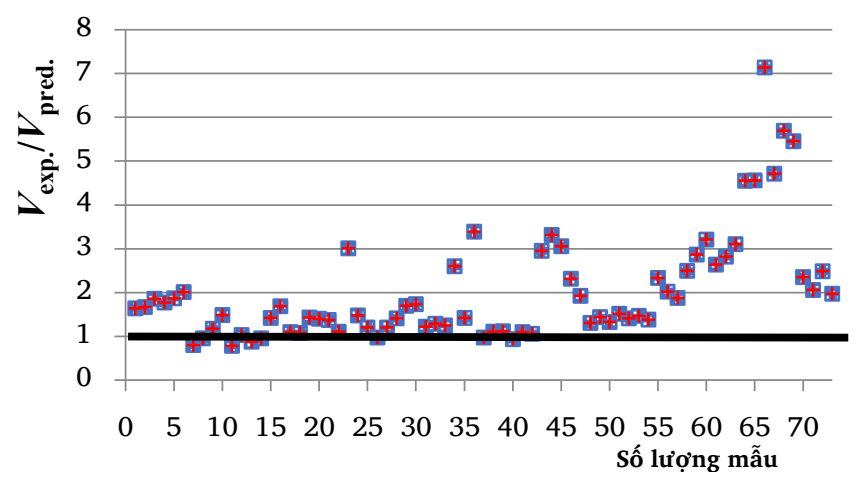

Hình 3. Tỷ lệ $\mathrm{V}_{\text {exp }} / \mathrm{V}_{\text {pred }}$. theo tiêu chuẩn JSCE-1997.

Có thể thấy, tính theo tiêu chuẩn CSA S806-02, số lượng mẫu có tỷ lệ $\mathrm{V}_{\text {exp }} / \mathrm{V}_{\text {pred. }}$ < 1 là 08 mẫu, chiếm $10,9 \%$ tổng số mẫu thử. Trong khi tính theo tiêu chuẩn ACI 440.1R-06 và JSCE-1997, số lượng mẫu có tỷ lệ $\mathrm{V}_{\text {exp }} \cdot \mathrm{V}_{\text {pred. }}$ < 1 là 06 mẫu $(8,2 \%)$ và 04 mẫu $(5,4 \%)$, tương ứng. Từ các phân tích trên cho thấy, mặc dù tiêu chuẩn CSA S806-02 có các chỉ số thống kê tốt hơn hai tiêu chuẩn ACI 440.1R-06 và JSCE-1997 nhưng số lượng mẫu dự báo có kết quả tính toán nhỏ hơn giá trị thực nghiệm lại lớn nhất.

\section{4. Đề xuất công thức dựa trên tiêu chuẩn TCVN 5574-2018 4.1. Cơ sở thiết lập công thức}

a) Dựa trên công thức xác định khả năng chịu cắt của dầm bê tông theo ACI 318-19 [18] và ACI 440.1R-06 [9]

trong đó: $f_{c}^{\prime}$ là cường độ chịu nén của bê tông mẫu trụ; $b_{w}$ là bề rộng tiết diện chữ nhật; $d$ là chiều cao làm việc của tiết diện; $c$ là chiều cao bê tông vùng nén; $n_{f}$ là tỷ lệ mô đun đàn hồi của cốt thanh FRP với mô đun đàn hồi của bê tông.

Theo Bảng 9, tiêu chuẩn $\mathrm{ACI} 440.1 \mathrm{R}-06$ cho rằng, vì mô đun đàn hồi của cốt dọc thanh FRP khá thấp so với cốt thép nên chiều cao vùng nén của bê tông giảm đáng kể, dẫn đến khả năng chịu cắt của bê tông vùng nén giảm so với dầm bê tông có cốt thép dọc. Do vậy để kể đến ảnh hưởng này, ACI 440.1R-06 thay vì sử dụng hệ số nhân 2 cho dầm bê tông cốt thép dọc họ sử dụng hệ số nhân $\left[\frac{2}{5} \sqrt{2 \rho_{f} n_{f}+\left(\rho_{f} n_{f}\right)^{2}}-\rho_{f} n_{f}\right]$ cho cốt dọc FRP. Có thể thấy khả năng chịu cắt của bê tông khi sử dụng cốt dọc FRP là hàm của hàm lượng và mô đun đàn hồi của cốt dọc thanh FRP và không phụ thuộc tỷ số $\frac{a}{d}$. Vì không xét tới ảnh hưởng của tỷ lệ $\frac{a}{d}$ nên khả năng chịu cắt của bê tông dự báo theo ACI 440.1R-06 thấp hơn nhiều khả năng chịu cắt từ kết quả thực nghiệm khi tỷ số $\frac{a}{d} \leq 1,5$ như đã chỉ ra trong mục 3.1.

b) Dựa trên công thức xác định khả năng chịu cắt của dầm bê tông theo CSA A23.3-04 [19] và CSA- S806-02 [10]

\section{Bảng 9.}

Công thức xác định khả năng chịu cắt của dầm bê tông theo ACI 31819 và ACI 440.1R-06.

\begin{tabular}{|c|c|}
\hline $\begin{array}{l}\text { ACI 318-Dầm bê } \\
\text { tông cốt thép dọc }\end{array}$ & ACI 440.1R- Dầm bê tông cốt FRP dọc \\
\hline$V_{c}=2 \sqrt{f_{c}^{\prime}} b_{\mathrm{w}} d$ & $\begin{array}{c}V_{c}=\frac{2}{5} \sqrt{f_{c}^{\prime}} b_{w} c \\
c=\left[\sqrt{2 \rho_{f} n_{f}+\left(\rho_{f} n_{f}\right)^{2}}-\rho_{f} n_{f}\right] d, n_{f}=\frac{E_{f}}{E_{c}}\end{array}$ \\
\hline
\end{tabular}

\section{Bảng 10.}

Công thức xác định khả năng chịu cắt của dầm bê tông theo CSA A23.304 và CSA- S806-02

\begin{tabular}{|c|c|}
\hline $\begin{array}{c}\text { CSA A23.3-04-Dầm bê } \\
\text { tông cốt thép dọc }\end{array}$ & CSA- S806-Dầm bê tông cốt FRP dọc \\
\hline$V_{c}=\varphi_{c} \lambda \beta \sqrt{f_{c}^{\prime}} b_{\mathrm{w}} d$ & $V_{c}=0,035 \lambda \varphi_{c}\left(f_{c}^{\prime} \rho_{f l} E_{f} \frac{V_{f} d}{M_{f}}\right)^{\frac{1}{3}} b_{\mathrm{w}} d$, \\
$\frac{V_{f}}{M_{f}}=\frac{1}{a}$ \\
\hline
\end{tabular}

Theo Bảng 10, có thể thấy công thức của CSA- S806 cho thấy khả năng chịu cắt của bê tông không những phụ thuộc vào hàm lượng và mô đun đàn hồi của cốt dọc FRP mà còn phụ thuộc tỷ số $\frac{d}{a}$ theo lũy thừa $\frac{1}{3}$. So với dầm bê tông cốt thép dọc, khả năng chịu cắt của dầm bê tông cốt dọc thanh FRP đã được hiệu chỉnh chủ yếu qua hệ số $\left(\rho_{f l} \cdot E_{f} \cdot \frac{d}{a}\right)^{\frac{1}{3}}$.

c) Theo đề nghị của Tottori và Wakui [16], khả năng chịu cắt của bê tông dầm bê tông cốt thanh FRP có thể bằng khả năng chịu cắt của bê tông dầm bê tông cốt thép nhân với hệ số $\left(\frac{E_{f}}{E_{s}}\right)^{1 / 3}$.

Từ các phân tích trên có thể thấy, các tiêu chuẩn tiên tiến trên thế giới đều đưa ra công thức dự báo khả năng chịu cắt của bê tông trong cấu kiện bê tông cốt dọc thanh FRP dựa trên công thức tính toán khả năng chịu cắt trong cấu kiện bê tông cốt thép thường nhưng có điều chỉnh thông qua hệ số phụ thuộc vào hàm lượng cốt dọc và mô đun đàn hồi của cốt dọc FRP. Do đó chúng tôi đề xuất sử dụng hệ số $\varphi_{F R P}$ tính đến ảnh hưởng của hàm lượng và độ cứng của cốt dọc thanh FRP đến khả năng chịu cắt của dầm. Hệ số $\varphi_{F R P}$ được xác định như trong mục dưới đây. 
Bảng 11.

Kết quả tính toán theo công thức đề xuất.

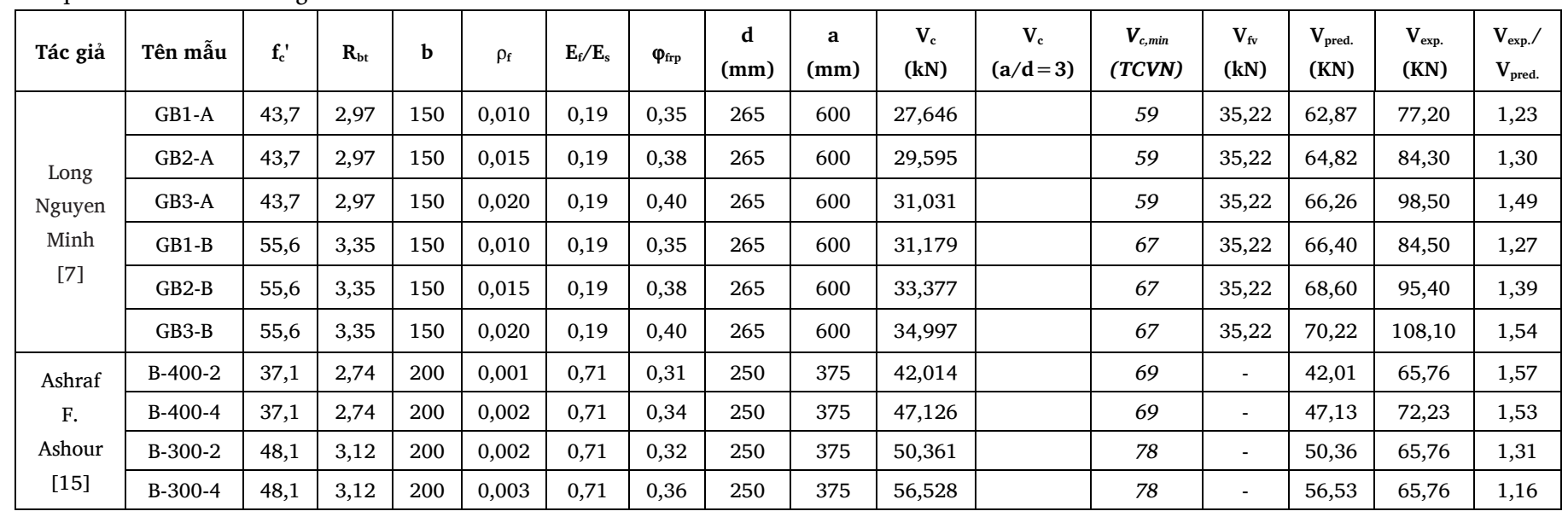

\section{Bảng 11 (tiếp).}

Kết quả tính toán theo công thức đề xuất.

\begin{tabular}{|c|c|c|c|c|c|c|c|c|c|c|c|c|c|c|c|}
\hline Tác giả & Tên mẫu & $\mathbf{f}_{\mathrm{c}}^{\prime}$ & $\mathbf{R}_{\mathrm{bt}}$ & b & $\rho_{\mathrm{f}}$ & $E_{\mathrm{f}} / \mathbf{E}_{\mathrm{s}}$ & $\varphi_{\text {frp }}$ & $\begin{array}{c}\mathrm{d} \\
(\mathrm{mm})\end{array}$ & $\begin{array}{c}\mathrm{a} \\
(\mathrm{mm})\end{array}$ & $\begin{array}{ll}\mathrm{V}_{\mathrm{c}} & (\mathrm{kN})\end{array}$ & $\mathrm{V}_{\mathrm{c}}(\mathrm{a} / \mathrm{d}=3)$ & $\begin{array}{c}\mathrm{V}_{\mathrm{fv}} \\
(\mathrm{kN})\end{array}$ & $\begin{array}{l}\mathrm{V}_{\text {pred. }} \\
(\mathrm{KN})\end{array}$ & $\mathrm{V}_{\text {exp. }}(\mathrm{KN})$ & $\mathrm{V}_{\text {exp. }} / \mathrm{V}_{\text {pred. }}$ \\
\hline \multirow{12}{*}{$\begin{array}{c}\text { Noor Azlina } \\
\text { A. Hamid } \\
{[13]}\end{array}$} & $\begin{array}{c}\text { G1B1-1.5- } \\
\text { 0.6R-S1 } \\
\end{array}$ & 30,0 & 2,46 & 200 & 0,006 & 0,28 & 0,35 & 362 & 550 & 60,838 & & 243,33 & 304,16 & 233,20 & 0,77 \\
\hline & $\begin{array}{c}\text { G1B2-1.5- } \\
0.8 R-S 1\end{array}$ & 30,0 & 2,46 & 200 & 0,008 & 0,28 & 0,36 & 362 & 550 & 63,826 & & 243,33 & 307,15 & 281,60 & 0,92 \\
\hline & $\begin{array}{c}\text { G1B3-1.5- } \\
0.6 \mathrm{R}-\mathrm{S} 2 \\
\end{array}$ & 30,0 & 2,46 & 200 & 0,006 & 0,28 & 0,35 & 362 & 550 & 60,838 & & 81,11 & 141,95 & 139,00 & 0,98 \\
\hline & $\begin{array}{c}\text { G1B4-1.5- } \\
0.8 R-S 2\end{array}$ & 30,0 & 2,46 & 200 & 0,008 & 0,28 & 0,36 & 362 & 550 & 63,826 & & 81,11 & 144,93 & 181,30 & 1,25 \\
\hline & $\begin{array}{c}\text { G1B7-3.0- } \\
0.6 \mathrm{R}-\mathrm{S} 2 \\
\end{array}$ & 30,0 & 2,46 & 200 & 0,006 & 0,28 & 0,35 & 362 & 1100 & 30,419 & & 81,11 & 111,53 & 92,80 & 0,83 \\
\hline & $\begin{array}{c}\text { G1B8-3.0- } \\
0.8 R-S 2 \\
\end{array}$ & 30,0 & 2,46 & 200 & 0,008 & 0,28 & 0,36 & 362 & 1100 & 31,913 & & 81,11 & 113,02 & 125,60 & 1,11 \\
\hline & $\begin{array}{c}\text { G2B1-1.6- } \\
\text { 1.2R-S1 } \\
\end{array}$ & 45,0 & 3,02 & 200 & 0,012 & 0,28 & 0,39 & 343 & 550 & 75,086 & & 230,55 & 305,64 & 255,00 & 0,83 \\
\hline & $\begin{array}{c}\text { G2B2-1.6- } \\
\text { 1.5R-S1 } \\
\end{array}$ & 45,0 & 3,02 & 200 & 0,015 & 0,28 & 0,40 & 343 & 550 & 77,931 & & 230,55 & 308,49 & 280,20 & 0,91 \\
\hline & $\begin{array}{c}\text { G2B3-1.6- } \\
1.2 \mathrm{R}-\mathrm{S} 2 \\
\end{array}$ & 45,0 & 3,02 & 200 & 0,012 & 0,28 & 0,39 & 343 & 550 & 75,086 & & 76,85 & 151,94 & 179,30 & 1,18 \\
\hline & $\begin{array}{c}\text { G2B4-1.6- } \\
\text { 1.5R-S2 } \\
\end{array}$ & 45,0 & 3,02 & 200 & 0,015 & 0,28 & 0,40 & 343 & 550 & 77,931 & & 76,85 & 154,78 & 219,30 & 1,42 \\
\hline & $\begin{array}{c}\text { G2B7-3.2- } \\
1.2 \mathrm{R}-\mathrm{S} 2\end{array}$ & 45,0 & 3,02 & 200 & 0,012 & 0,28 & 0,39 & 343 & 1100 & 37,543 & 40,134 & 76,85 & 116,99 & 138,50 & 1,18 \\
\hline & $\begin{array}{c}\text { G2B8-3.2- } \\
1.5 R-S 2 \\
\end{array}$ & 45,0 & 3,02 & 200 & 0,015 & 0,28 & 0,40 & 343 & 1100 & 38,966 & 41,654 & 76,85 & 118,51 & 140,10 & 1,18 \\
\hline \multirow{7}{*}{$\begin{array}{c}\text { A.Ghani } \\
\text { Razaqpur } \\
{[5]}\end{array}$} & BR1 & 40,5 & 2,86 & 200 & 0,003 & 0,73 & 0,35 & 225 & 601 & 25,280 & & - & 25,28 & 36,11 & 1,43 \\
\hline & BR2/BA2 & 49,0 & 3,15 & 200 & 0,005 & 0,73 & 0,39 & 225 & 601 & 31,212 & & - & 31,21 & 46,95 & 1,50 \\
\hline & BR3 & 40,5 & 2,86 & 200 & 0,006 & 0,73 & 0,41 & 225 & 601 & 29,490 & & - & 29,49 & 47,23 & 1,60 \\
\hline & BR4 & 40,5 & 2,86 & 200 & 0,009 & 0,73 & 0,43 & 225 & 601 & 31,180 & & - & 31,18 & 42,71 & 1,37 \\
\hline & BA1 & 40,5 & 2,86 & 200 & 0,005 & 0,73 & 0,39 & 225 & 410 & 41,628 & & - & 41,63 & 96,18 & 2,31 \\
\hline & BA3 & 40,5 & 2,86 & 200 & 0,005 & 0,73 & 0,39 & 225 & 801 & 21,282 & 25,255 & - & 25,25 & 46,99 & 1,86 \\
\hline & BA4 & 40,5 & 2,86 & 200 & 0,005 & 0,73 & 0,39 & 225 & 1013 & 16,836 & 25,255 & - & 25,25 & 38,45 & 1,52 \\
\hline \multirow{3}{*}{$\begin{array}{c}\text { Evan } \\
\text { C.Bentz } \\
{[1]}\end{array}$} & L05-0 & 46,0 & 3,05 & 450 & 0,005 & 0,19 & 0,31 & 937 & 3050 & 185,111 & 200,849 & - & 200,85 & 135,00 & 0,67 \\
\hline & M05-0 & 35,0 & 2,66 & 450 & 0,005 & 0,19 & 0,31 & 438 & 1525 & 70,564 & 81,896 & - & 81,90 & 86,00 & 1,05 \\
\hline & S05-0 & 35,0 & 2,66 & 450 & 0,005 & 0,19 & 0,31 & 194 & 762 & 27,705 & 36,273 & - & 36,27 & 54,50 & 1,50 \\
\hline
\end{tabular}




\begin{tabular}{|c|c|c|c|c|c|c|c|c|c|c|c|c|c|c|c|}
\hline Tác giả & Tên mẫu & $f_{c}^{\prime}$ & $\mathbf{R}_{\mathrm{bt}}$ & b & $\rho_{\mathrm{f}}$ & $\mathbf{E}_{f} / \mathbf{E}_{s}$ & $\varphi_{\text {frp }}$ & $\underset{(\mathrm{mm})}{\mathrm{d}}$ & $\begin{array}{c}\mathrm{a} \\
(\mathrm{mm})\end{array}$ & $\begin{array}{ll}\mathrm{V}_{\mathrm{c}} & (\mathrm{kN})\end{array}$ & $\mathrm{V}_{\mathrm{c}}(\mathrm{a} / \mathrm{d}=3)$ & $\begin{array}{c}\mathrm{V}_{\mathrm{fv}} \\
(\mathrm{kN})\end{array}$ & $\begin{array}{l}\mathrm{V}_{\text {pred. }} \\
\text { (KN) }\end{array}$ & $\mathrm{V}_{\text {exp. }}(\mathrm{KN})$ & $\mathrm{V}_{\text {exp. }} / \mathrm{V}_{\text {pred. }}$ \\
\hline & L05-1 & 46,0 & 3,05 & 450 & 0,005 & 0,19 & 0,31 & 937 & 3050 & 185,111 & & 5,40 & 190,51 & 237,00 & 1,24 \\
\hline & L20-0 & 36,0 & 2,70 & 450 & 0,020 & 0,19 & 0,39 & 857 & 3050 & 172,596 & 204,752 & - & 204,75 & 232,00 & 1,13 \\
\hline & M20-0 & 35,0 & 2,66 & 450 & 0,020 & 0,19 & 0,39 & 405 & 1525 & 76,014 & 95,408 & - & 95,41 & 138,00 & 1,45 \\
\hline & S20-0 & 35,0 & 2,66 & 450 & 0,020 & 0,19 & 0,39 & 188 & 762 & 32,780 & 44,288 & - & 44,29 & 74,00 & 1,67 \\
\hline & M20-1 & 35,0 & 2,66 & 450 & 0,020 & 0,19 & 0,39 & 405 & 1525 & 76,014 & 95,408 & 2,33 & 97,74 & 154,00 & 1,58 \\
\hline & $\mathrm{L} 20-2$ & 42,0 & 2,92 & 450 & 0,020 & 0,19 & 0,39 & 857 & 3050 & 186,425 & 221,157 & 9,88 & 231,04 & 690,00 & 2,99 \\
\hline \multirow{9}{*}{$\begin{array}{l}\text { Mohsen } \\
\text { A.Issa } \quad[2\end{array}$} & 5-10N5 & 35,9 & 2,70 & 300 & 0,008 & 0,27 & 0,36 & 170 & 961 & 13,095 & 24,663 & - & 24,66 & 29,30 & 1,19 \\
\hline & 5-13N5 & 35,9 & 2,70 & 300 & 0,013 & 0,26 & 0,39 & 170 & 961 & 14,156 & 17,103 & - & 17,10 & 38,70 & 2,26 \\
\hline & 5-16N5 & 35,9 & 2,70 & 300 & 0,021 & 0,26 & 0,42 & 170 & 961 & 15,219 & 28,663 & - & 28,66 & 45,20 & 1,58 \\
\hline & 2-13SB1 & 35,9 & 2,70 & 200 & 0,005 & 0,26 & 0,33 & 275 & 413 & 48,832 & & 72,07 & 120,90 & 147,50 & 1,22 \\
\hline & 3-13SB1 & 35,9 & 2,70 & 200 & 0,007 & 0,26 & 0,35 & 275 & 413 & 52,193 & & 72,07 & 124,27 & 195,80 & 1,58 \\
\hline & 3-16SB1 & 35,9 & 2,70 & 200 & 0,012 & 0,26 & 0,38 & 270 & 405 & 55,216 & & 70,76 & 125,98 & 214,00 & 1,70 \\
\hline & 2-25B1 & 35,9 & 2,70 & 200 & 0,019 & 0,24 & 0,41 & 265 & 398 & 58,317 & & 69,45 & 127,77 & 192,10 & 1,50 \\
\hline & 3-16B2 & 35,9 & 2,70 & 200 & 0,012 & 0,26 & 0,38 & 270 & 675 & 33,130 & & 70,76 & 103,89 & 134,70 & 1,30 \\
\hline & 3-16B3 & 35,9 & 2,70 & 200 & 0,012 & 0,26 & 0,38 & 270 & 945 & 23,664 & 27,608 & 70,76 & 98,37 & 91,50 & 0,93 \\
\hline
\end{tabular}

\section{Bảng 11 (tiếp).}

Kết quả tính toán theo công thức đề xuất.

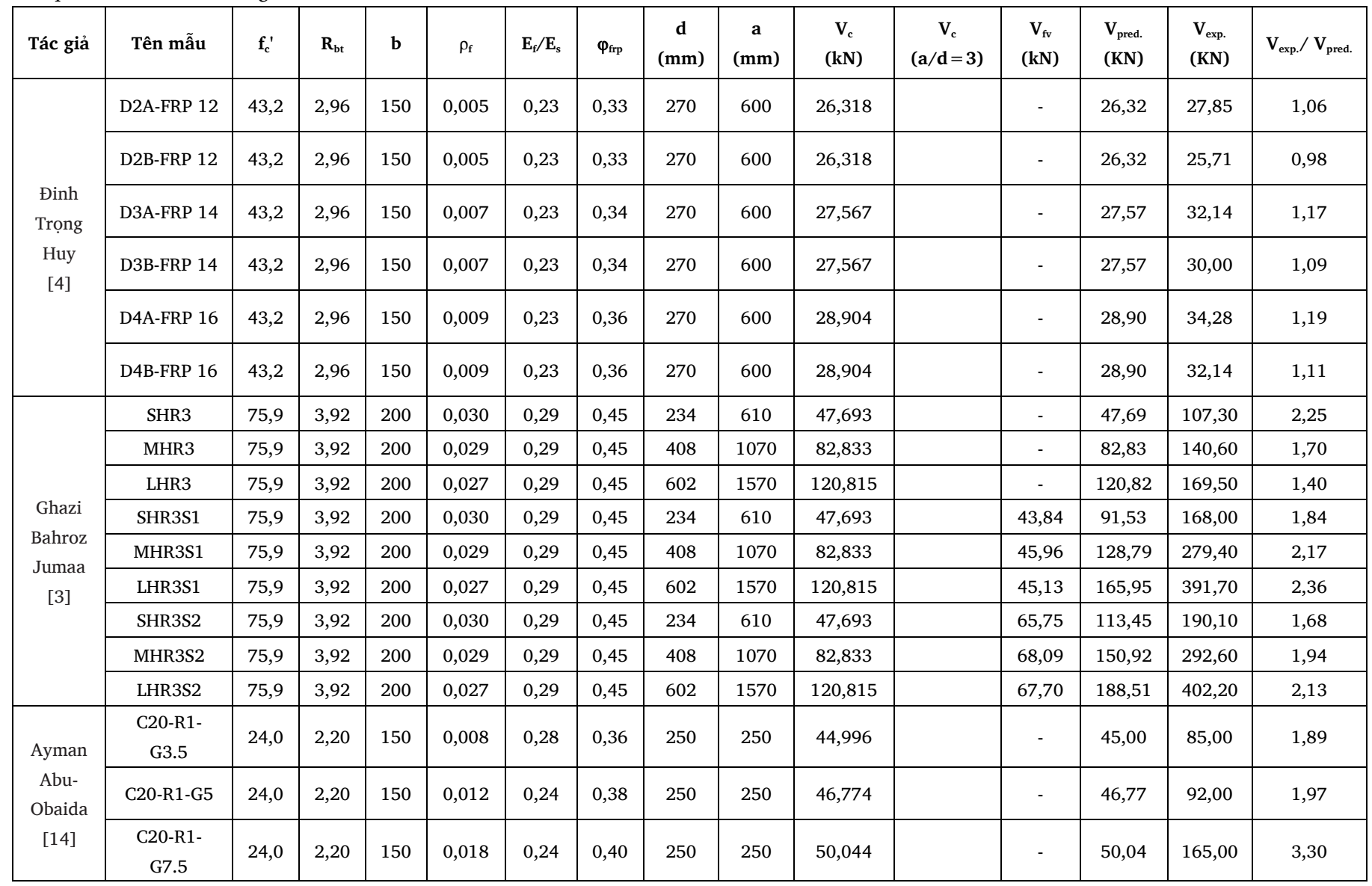




\begin{tabular}{|c|c|c|c|c|c|c|c|c|c|c|c|c|c|c|c|}
\hline Tác giả & Tên mẫu & $\mathbf{f}_{\mathrm{c}}^{\prime}$ & $\mathbf{R}_{\mathrm{bt}}$ & b & $\rho_{\mathrm{f}}$ & $\mathbf{E}_{\mathrm{f}} / \mathbf{E}_{\mathrm{s}}$ & $\varphi_{\text {frp }}$ & $\begin{array}{c}\mathrm{d} \\
(\mathrm{mm})\end{array}$ & $\begin{array}{c}\mathrm{a} \\
(\mathrm{mm})\end{array}$ & $\begin{array}{c}\mathrm{V}_{\mathrm{c}} \\
(\mathrm{kN})\end{array}$ & $\begin{array}{c}V_{c} \\
(a / d=3)\end{array}$ & $\begin{array}{c}\mathrm{V}_{\mathrm{fv}} \\
(\mathrm{kN})\end{array}$ & $\begin{array}{l}V_{\text {pred. }} \\
(\mathrm{KN})\end{array}$ & $\begin{array}{l}\mathrm{V}_{\text {exp. }} \\
(\mathrm{KN})\end{array}$ & $\mathrm{V}_{\text {exp. }} / \mathrm{V}_{\text {pred. }}$ \\
\hline & $\begin{array}{c}\text { C20-R1.5- } \\
\text { G3.5 }\end{array}$ & 24,0 & 2,20 & 150 & 0,008 & 0,28 & 0,36 & 250 & 375 & 29,997 & & - & 30,00 & 88,00 & 2,93 \\
\hline & $\begin{array}{c}\text { C20-R1.5- } \\
\text { G5 }\end{array}$ & 24,0 & 2,20 & 150 & 0,012 & 0,24 & 0,38 & 250 & 375 & 31,183 & & - & 31,18 & 115,00 & 3,69 \\
\hline & $\begin{array}{c}\text { C20-R1.5- } \\
\text { G7.5 }\end{array}$ & 24,0 & 2,20 & 150 & 0,018 & 0,24 & 0,40 & 250 & 375 & 33,363 & & - & 33,36 & 126,00 & 3,78 \\
\hline & \multicolumn{14}{|c|}{ Giá trị trung bình } & 1,57 \\
\hline
\end{tabular}

\subsection{Thiết lập công thức}

Giả thiết thiết lập công thức:

- Ở trạng thái tải trọng cực hạn, khả năng chịu cắt và uốn của dầm là do sự tham gia chịu lực của vùng bê tông chịu nén chưa bị nứt, cốt ngang cắt qua vết nứt nghiêng và sự truyền lực cắt qua cốt dọc thanh FRP; Vết nứt nghiêng góc $45^{\circ}$ theo phương trục dầm;

- Nếu sử dụng cốt ngang thanh FRP thì quan hệ ứng suất-biến dạng của nó là tuyến tính đến khi bị phá hoại;

Dựa trên các công thức xác định khả năng chịu cắt của bê tông vùng nén cho dầm bê tông cốt thép theo TCVN 5574-2018 [12], công thức xác định khả năng chịu cắt của bê tông vùng nén cho dầm cốt dọc thanh FRP như sau:

$$
V_{c}=\frac{1,5 R_{b t} b d^{2}}{a} \varphi_{F R P} \text {, điều kiện } \frac{a}{d} \geq 1
$$

Trong đó:

- 1,5 là hệ số kể đến ảnh hưởng của cốt thép dọc, lực bám dính [12].

- Nếu sử dụng cường độ chịu kéo chẻ tách, $\mathrm{f}_{\mathrm{ct}}$ thay cho cường độ chịu kéo trực tiếp, $\mathrm{R}_{\mathrm{bt}}$ thì có thể lấy $\mathrm{R}_{\mathrm{bt}}=0,9 f_{c t}$ [17]; Trường hợp không có kết quả thí nghiệm xác định cường độ chịu kéo thì có thể tính gần đúng cường độ chịu kéo $\mathrm{R}_{\mathrm{bt}} \approx 0,5 \mathrm{f}_{\mathrm{c}}^{{ }^{\prime} 1 / 2}[18]$.

- $\varphi_{F R P}=\left(\frac{\rho_{f} \cdot E_{f}}{E_{s}}\right)^{\frac{1}{6}}$ là hệ số kể đến ảnh hưởng của cốt dọc FRP. Số mũ $\frac{1}{6}$ được xác định bằng thử dần thông qua các số liệu thực nghiệm trong Bảng 1 đến Bảng 3 .

Trong công thức (14) khoảng cách từ điểm đặt lực tập trung đến gối tựa, a, chính là chiều dài hình chiếu tiết diện nghiêng nguy hiểm lên phương dọc trục dầm, C (theo TCVN5574-2018). Trong trường hợp dầm có góc nghiêng vết nứt do phá hoại cắt nhỏ hơn $45^{\circ}$, theo TCVN5574-2018 [12] khi đó lấy giá trị a $(C)$ trong khoảng $\mathrm{d}\left(\mathrm{h}_{\mathrm{o}}\right)$ và $3 \mathrm{~d}$ $\left(3 \mathrm{~h}_{\mathrm{o}}\right)$, với $\mathrm{h}_{\mathrm{o}}$ là chiều cao làm việc của dầm.

Lấy $E_{s}=200000 \mathrm{MPa}$ thay vào biểu thức $\varphi_{F R P}$ và công thức (14) có công thức gần đúng:

$$
\begin{aligned}
& V_{c}=\frac{1}{5} \frac{R_{b t} b d^{2}}{a}\left(\rho_{f} \cdot E_{f}\right)^{1 / 6} \\
& \text { Khả năng chịu cắt của cốt đai: } \quad V_{f}=\frac{A_{f v} f_{f v} d}{s} \\
& \text { Khả năng chịu cắt danh nghĩa của dầm: } V_{u}=V_{c}+V_{f}
\end{aligned}
$$

\section{3. Đánh giá công thức đề xuất}

Kết quả tính toán theo công thức đề xuất được thể hiện ở Bảng 11. So sánh kết quả tính toán theo công thức đề xuất với thực nghiệm được thể hiện ở Bảng 12. Tỷ lệ $\mathrm{V}_{\text {exp }} / \mathrm{V}_{\text {pred }}$. theo công thức đề xuất được thể hiện ở Hình 4. So sánh chỉ số thống kê của công thức đề xuất với các tiêu chuẩn cho toàn bộ mẫu được thể hiện ở Bảng 13.

Bảng 12.

So sánh kết quả tính toán theo công thức đề xuất với thực nghiệm Công thức đề xuất $\mathrm{V}_{\mathrm{exp}}$. $/ \mathrm{V}_{\text {pred }}$.

\begin{tabular}{|c|c|c|c|c|}
\hline \multirow{2}{*}{ Công thức đề xuất } & \multicolumn{4}{|c|}{$\mathrm{V}_{\text {exp }} / \mathrm{V}_{\text {pred }}$. } \\
\cline { 2 - 5 } & $\overline{\mathrm{X}}$ & $\mathrm{SD}$ & $\mathrm{CoV}$ & $\mathrm{AAE}$ \\
\cline { 2 - 5 } & 1,57 & 0,62 & 0,40 & 50,50 \\
\hline
\end{tabular}

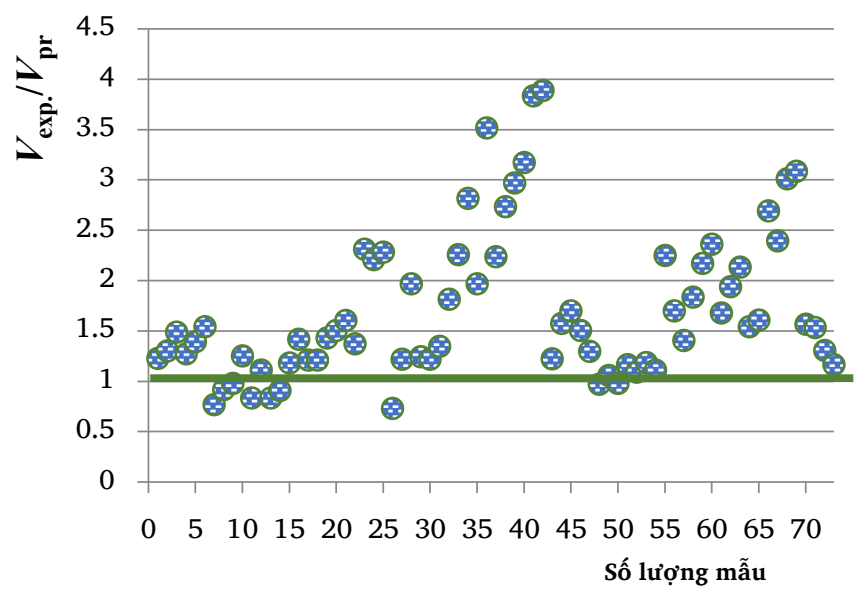

Hình 4. Tỷ lệ $\mathrm{V}_{\text {exp}} / \mathrm{V}_{\text {pred}}$. theo công thức đề xuất.

\section{Bảng 13.}

So sánh chỉ số thống kê của công thức đề xuất với các tiêu chuẩn.

\begin{tabular}{|c|c|c|c|c|}
\hline \multirow{2}{*}{ Phương pháp } & \multicolumn{4}{|c|}{$\mathrm{V}_{\text {exp }} / \mathrm{V}_{\text {pred }} \cdot$} \\
\cline { 2 - 5 } & $\overline{\mathrm{X}}$ & $\mathrm{SD}$ & $\mathrm{CoV}$ & $\mathrm{AAE}$ \\
\hline ACI440.1R & 2,25 & 1,68 & 0,73 & 66,30 \\
\hline CSA S806 & 1,79 & 0,95 & 0,53 & 65,51 \\
\hline JSCE-1197 & 2,01 & 1,23 & 0,61 & 63,15 \\
\hline Đề xuất & 1,57 & 0,62 & 0,40 & 50,50 \\
\hline
\end{tabular}


So sánh Bảng 12 với các Bảng 4 và Bảng 8 thấy rằng, các chỉ số thống kê thu được từ công thức đề xuất là nhỏ nhất. Mặt khác số lượng mẫu có tỷ lệ $\mathrm{V}_{\text {exp }} / \mathrm{V}_{\text {pred. }}$ < 1 là 06 mẫu (chiếm 8,2 \% như ở Hình 4), tương đương tiêu chuẩn ACI 440.1R.

\section{5- Kết luận và kiến nghị}

Từ các phân tích, tính toán, tổng hợp và đề xuất công thức dự báo khả năng chịu cắt của dầm bê tông cốt dọc thanh FRP theo TCVN 5574:2018 ở trên, so sánh kết quả tính toán với 73 kết quả thực nghiệm của nhiều tác giả khác nhau và trong phạm vi khảo sát cho thấy:

Các tiêu chuẩn thiết kế khả năng chịu cắt cho dầm bê tông cốt dọc thanh FRP, cốt đai thanh FRP hoặc cốt đai thép thường đều cho kết quả khá an toàn so với kết quả thực nghiệm. Tuy nhiên hệ số biến động, độ lệch chuẩn và sai số tuyệt đối trung bình khá cao;

Hai tiêu chuẩn ACI 440.1R-06 và JSCE-1997 có các chỉ số thống kê cao hơn tiêu chuẩn CSA S806-02 (trung bình lớn hơn lần lượt là $35 \%$ và 13 \% tương ứng) và cho thấy là quá an toàn, dẫn đến lãng phí vật liệu;

Công thức đề xuất dự báo khả năng chịu cắt cho dầm bê tông cốt FRP phù hợp với các kết quả thực nghiệm và cho các chỉ số thống kê nhỏ nhất. Công thức có hình thức tương tự như cho dầm bê tông cốt thép thường nhưng có thêm hệ số điều chỉnh (hệ số nhân) $\varphi_{\mathrm{FRP}}$ khi sử dụng cốt dọc thanh FRP.

Công thức đề xuất cho phép thiết kế kinh tế hơn với các cấu kiện dầm bê tông cốt thanh FRP chịu cắt tuy nhiên cần kiểm chứng công thức đề xuất trên phạm vi dữ liệu thực nghiệm rộng hơn bao gồm cả cốt thanh AFRP.

Với nhiều ưu điểm của cốt FRP, tiêu chuẩn của Việt Nam cần sớm có các chỉ dẫn thiết kế đối với kết cấu dầm bê tông cốt thanh FRP và có thể xem xét áp dụng công thức đề xuất trong tính toán khả năng chịu cắt của loại dầm này.

\section{Tài liệu tham khảo}

[1] Bentz, E.C., L. Massam, and M.P. Collins, Shear Strength of Large Concrete Members with FRP Reinforcement. Journal of Composites for Construction, 2010. 14(6): p. 637-646.

[2] Issa, M.A., T. Ovitigala, and M. Ibrahim, Shear Behavior of Basalt Fiber Reinforced Concrete Beams with and without Basalt FRP Stirrups. Journal of Composites for Construction, 2016. 20(4): p. 04015083.

[3] Jumaa, G.B. and A.R. Yousif, Size effect on the shear failure of high-strength concrete beams reinforced with basalt FRP bars and stirrups. Construction and Building Materials, 2019. 209: p. 77-94.

[4] Huy, Đ.T., Nghiên cứu khả năng chịu cắt của dầm bê tông cốt sợi thủy tinh, Luận văn thạc sỹ kỹ thuật, 2015, Đại học Kiến Trúc Hà Nội.

[5] Razaqpur, A.G. and S. Spadea, Shear Strength of FRP Reinforced Concrete Members with Stirrups. Journal of Composites for Construction, 2015. 19(1): p. 04014025.

[6] Kueres, S. and J. Hegger, Variable strut inclination model for shear design of FRP reinforced concrete members with shear reinforcement. Engineering Structures, 2020. 206: p. 110154.

[7] Rovnak, M. and L. Nguyen-Minh, Shear resistance of GFRP-reinforced concrete beams. Magazine of Concrete Research, 2011. 63: p. 215-233.
[8] Hoult, N.A., et al., Does the Use of FRP Reinforcement Change the One-Way Shear Behavior of Reinforced Concrete Slabs? Journal of Composites for Construction, 2008. 12(2): p. 125-133.

[9] ACI (American Concrete Institute), Guide for the Design and Construction of Structural Concrete Reinforced with FRP Bars, ACI 440.1R-06, 2006, Farmington Hills, MI.

[10] CSA (Canadian Standards Association), Design and construction of building components with fiber-reinforced polymers, CAN/CSAS806-02, 2002: Mississauga,ON, Canada.

[11] Japan Society of Civil Engineers (JSCE), Recommendation for design and construction of concrete structures using continuous fiber reinforcing materials, 1997: Research Committee on Continuous Fiber Reinforced Material, Tokyo

[12] TCVN 5574-2018, Kết cấu bê tông và bê tông cốt thép - tiêu chuẩn thiết kế, 2018: Bộ Xây Dựng Hà Nội.

[13] Noor Azlina A. Hamid, et al., Shear Strength Prediction for Concrete Beams Reinforced with GFRP Bars. ISCEE 2016.

[14] Abu-Obaida, A., B. El-Ariss, and T. El-Maaddawy, Behavior of Short-Span Concrete Members Internally Reinforced with Glass Fiber-Reinforced Polymer Bars. Journal of Composites for Construction, 2018. 22(5).

[15] Ashour, A.F. and I.F. Kara, Size effect on shear strength of FRP reinforced concrete beams. Composites Part B: Engineering, 2014. 60: p. 612-620.

[16] Tottori S and Wakui H, Shear capacity of RC and PC beams using FRP reinforcement. In: Fiber-reinforced-plastic reinforcement for concrete structures, SP-138. Detroit: American Concrete Institute, 1993: p. 615-32.

[17] P. Bamforth, et al., Properties of Concrete for use in Eurocode 2. The Concrete Centre, 2008.

[18] Building Code Requirements for Structural Concrete (ACI 318-19), Reported by ACI Committee 318.

[19] CSA "Design of concrete structures", Standard A23.3-04. 